Canadian

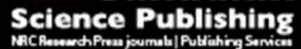

Canadian Journal of Forest Research Revue canadienne de recherche forestière

\title{
Influence of Hemlock Woolly Adelgid Infestation on the Physiological and Reflectance Characteristics of Eastern Hemlock
}

\begin{tabular}{|r|l|}
\hline Journal: & Canadian Journal of Forest Research \\
\hline Manuscript ID & cjfr-2015-0328.R1 \\
\hline Danuscript Type: & Article \\
\hline Complete List of Authors: & $\begin{array}{l}\text { Williams, Justin; USDA Forest Service, Southern Research Station } \\
\text { Hanavan, Ryan; US Forest Service, Forest Health and Protection } \\
\text { Rock, Barrett; University of New Hampshire, Earth Systems Research } \\
\text { Center } \\
\text { Minocha, Subhash; University of New Hampshire, Department of Biological } \\
\text { Sciences } \\
\text { Linder, Ernst; University of New Hampshire, Department of Mathmatics and } \\
\text { Statistics }\end{array}$ \\
\hline Keyword: & $\begin{array}{l}\text { remote sensing, vegetation indices, fluorescence, chlorophyll, Adelges } \\
\text { tsugae }\end{array}$ \\
\hline
\end{tabular}

SCHOLARONE ${ }^{m}$

Manuscripts 

Influence of Hemlock Woolly Adelgid Infestation on the Physiological and Reflectance Characteristics of Eastern Hemlock

\section{Corresponding Author:}

4 Justin P. Williams ${ }^{1}$ : Department of Natural Resources and the Environment, James Hall,

5 University of New Hampshire Durham, New Hampshire 03824 USA

\section{Co-Authors:}

7 Ryan P. Hanavan: U.S. Forest Service 271 Mast Rd. Durham, New Hampshire 03824 USA;

$8 \quad \underline{\text { rhanavan02@fs.fed.us }}$

9 Barrett N. Rock: Earth Systems Research Center, Morse Hall, University of New Hampshire

10 Durham, New Hampshire 03824 USA; rock.bg@,comcast.net

11 Subhash C. Minocha: Department of Biological Sciences, Rudman Hall, University of New

12 Hampshire Durham, New Hampshire 03824 USA; subhash.minocha@unh.edu

13 Ernst Linder: Department of Mathematics and Statistics, Kingsbury Hall, University of New

14 Hampshire Durham, New Hampshire 03284 USA; elinder@unh.edu

\footnotetext{
${ }^{1}$ Current Affiliation: U.S. Forest Service Southern Research Station 775 Stone Blvd., Box 9861 Mississippi State, Mississippi 39762 USA; justinwilliams@fs.fed.us; Tel. (662) 325-8006
} 


\section{Abstract}

The hemlock woolly adelgid (HWA) (Adelges tsugae) is an invasive insect in the eastern

17 United States. Since its initial detection in Richmond, Virginia, in 1951, HWA has spread to half

of the eastern hemlock natural range. Detection of early infestation symptoms via remote sensing requires the knowledge of the changes in reflectance resulting from physiological changes in the host as inflicted by the insect, and the selection of equipment with the appropriate

21 sensor characteristics. Laboratory based reflectance measurements of infested and non-infested

22 hemlock foliage collected from four sites in southern New Hampshire and Maine occurred

23 biweekly over 6 months in 2012, and weekly over 5 weeks in 2013. Vegetation indices (REIP,

24 NDVI, MSI and NIR3/1) were associated with concurrent chlorophyll and moisture content data.

25 Infested first year foliage contained greater concentrations of chlorophyll and moisture resulting

26 in reduced visible spectral reflectance, greater REIP and NDVI values, and lower MSI and NIR

$273 / 1$ values than non-infested foliage. Furthermore, fluorescence measurements indicated greater

28 photosystem function during the early stages of infestation, suggesting a possible compensatory

29 response by hemlock to infestation. Significant differences in reflectance between infested and

30 non-infested foliage were observed in late June and July in the weeks immediately following

31 HWA settlement on new growth. Implementing these observations during remote sensing

32 mission planning may increase the likelihood of detecting early HWA infestation symptoms at

33 landscape scales.

34 Keywords: Adelges tsugae, Hemlock Woolly Adelgid, remote sensing, vegetation indices,

35 fluorescence, chlorophyll 


\section{Introduction}

Eastern hemlock (Tsuga canadensis (L.) Carr.) is a foundation tree species in the northeastern United States (Ellison et al. 2005). Often found on steep slopes and in riparian areas, hemlocks filter water, retain soil, and provide shade to streams and habitat to wildlife

40 (Bonneau et al. 1999). Currently, the vigor of the eastern hemlock population is declining due to 41 multiple stressors like the elongate hemlock scale (Homoptera: Fiorinia externa Ferris), hemlock

42 tip blight (Sirococcus tsugae), and more prominently the hemlock woolly adelgid (HWA)

43 (Hemiptera: Adelges tsugae Annand).

Multiple studies have been published documenting the biology and ecology of HWA

45 (McClure and Cheah 1999), its effects on needle chemistry (Radville et al. 2011), volatiles

46 (Pezet et al. 2013), water and carbon relations (Domec et al. 2013), and radial growth (Davis et

47 al. 2007). The effects of HWA infestation on hemlock reflectance features has received little

48 attention, focusing only on airborne hyperspectral data collection and modeling (Hanavan et al.

49 2015, Pontius et al. 2005a, 2005b).

The purpose of this study was to examine the effects of HWA infestation on hemlock

51 reflectance over time and how those changes related to leaf biophysical variables. The ultimate

52 goal was to determine an optimal time period in the growing season for discrimination between

53 infested and non-infested hemlock stands with either narrow or broadband remote sensing

54 platforms. Our objectives were to:

55 1. Determine when hemlock reflectance was most affected by HWA infestation through both long (6 months) and short (5 weeks) term measurement intervals. 
2. Determine whether HWA infestation impacted needle chlorophyll concentration and function through pigment extraction, reflectance and fluorescence measurements.

3. Determine whether HWA infestation impacted foliar moisture content through reflectance, fresh weight and dry weight measurements.

Health and growth of vegetation is dependent on the process of photosynthesis.

Disruption of the photosynthetic apparatus leading to reduced plant vigor can be induced through a multitude of biotic and abiotic stressors. Insect infestations are a biotic stressor whereby feeding is accomplished through ingestion of foliage, phloem sap or xylem sap. Hemlock woolly adelgids feed from the xylem ray parenchyma cells which transfer water, nutrients and photosynthate solution, as well contain stored starch reserves within the parenchyma cell walls (Young et al. 1995). Feeding by HWA can cause premature needle drop, dieback of major limbs, and mortality within 4 to 15 years after infestation (McClure 1987). However, several studies of the effects of HWA on foliar chemistry have indicated that infested foliage had greater concentrations of nitrogen than non-infested foliage (Domec et al. 2013, Miller-Pierce et al. 2010, Pontius et al. 2006). Since foliar nitrogen is primarily bound to photosynthetic enzymes, those authors hypothesized that HWA infested trees may have greater photosynthetic capacity than non-infested trees. We set out to test those hypotheses through both direct (pigment extraction) and indirect (reflectance) measurements of chlorophyll concentration in infested and non-infested hemlock foliage. In addition, we evaluated photosystem integrity of infested and non-infested hemlock needles through fluorescence data to determine whether infestation affected overall chlorophyll function. 
Reflectance properties of plants are controlled by pigments, cellular structure, and the

79 amount of moisture filled intercellular air spaces contained within the spongy mesophyll (Gates

80

81

\section{2}

83

84

et al. 1965). Changes in these properties due to HWA feeding would induce spectral shifts that could be compared to "healthy" spectra. In addition, many vegetation indices (VIs) that estimate biophysical parameters from spectral reflectance data have been developed; this project utilized four VIs to characterize possible differences in hemlock foliar health: Red Edge Inflection Point (REIP) (Horler et al. 1983), a measure of chlorophyll content; Normalized Difference Vegetation Index (NDVI) (Rouse et al. 1974), a measure of chlorophyll content and canopy biomass; Near Infrared (NIR) 3/1 Ratio (Bubier et al. 1997), a measure of foliar maturity; and the Moisture Stress Index (MSI) (Rock et al. 1986), a measure of leaf turgor.

Reflectance measuring sensors have the ability to detect canopy photosynthetic pigment and moisture statuses at varying spectral, spatial, and temporal resolutions. Identifying sensor traits that would be advantageous in detecting forests of declining health is paramount in remote sensing mission planning. We set out to determine how HWA infestation affected hemlock reflectance properties through changes in chlorophyll concentration and needle turgor, thereby inferring an appropriate spectral resolution for discriminating between HWA infested and noninfested forests. We also aimed to identify when the differences between infested and noninfested foliage were greatest by observing changes over time, thereby inferring the ideal timeframe for data collection and determining whether the duration of the spectral response would influence decisions concerning sensor temporal resolution. Given the potential for the rapid spread of HWA infestations due to its biannual and asexual lifecycle (McClure 1987), applying these observations to future remote sensing mission planning may increase the likelihood of detecting forests infested with HWA prior to major defoliation and or mortality. 
101

102

\section{Methods}

\subsection{Defoliation Ratings}

Single $45 \mathrm{~m}$ radius plots were established at each of four locations (Fig. 1) (Table 1): Massabesic Experimental Forest in Alfred, Maine (N43.43927, W70.67931) which has been infested with HWA since 2012; Rachael Carson Wildlife Refuge on Cutts Island, Kittery, Maine (N43.09558, W70.67142) which has been infested with HWA since 2003; Russell-Abbott State Forest in Wilton, New Hampshire (N42.79048, W71.76155) which has been infested with HWA since 2011; and Northwood Meadows State Park in Northwood, New Hampshire (N43.20466, W71.19827) where HWA presence had not yet been detected as of 2015. Plots were established in June 2012; all trees $10 \mathrm{~cm}$ diameter at breast height (DBH) and over were measured, and each hemlock was given a unique identification number and rated for defoliation. Defoliation ratings were estimated based on the percent defoliation of the live crown: $1=<25 \%$ defoliation; $2=26$ - 50\% defoliation; $3=51-75 \%$ defoliation; $4=76-99 \%$ defoliation; $5=100 \%$ defoliation (dead) (Orwig \& Foster 1998). Defoliation ratings were determined through consensus by a twoperson crew. The same crew was used to rate every tree in this study.

\subsection{Reflectance and Spectral Indices}

In 2012 hemlock foliage from plots were sampled bi-weekly from the end of June (post HWA emergence) through the second week of December. Two tagged hemlocks were chosen randomly at each plot; due to the lottery style selection of numbers some hemlocks were sampled more than once over the seven month period. Light-exposed terminal hemlock branches were sampled with pole pruners from the lower, middle, and upper live crown in each cardinal direction. Samples were stored and transported to the lab in coolers with blue ice. Infestation 
123 status was determined by thoroughly checking each sample for signs of HWA. Samples were

124 then separated into first year and second year branch segments for spectral analysis. Reflectance 125 measurements were taken within 24 to 48 hours of foliage being cut from the tree. Foliage was 126 frozen for pigment extractions following spectral analysis.

First and second year branch segments were separately arranged, in an optically dense layer, in petri dishes spray painted in flat black color. Spectral reflectance was measured using a 129 Visible InfRared Intelligent Spectrometer (VIRIS GER 2600; Geophysical Environmental 130 Research Corporation, Millbrook, NY, USA); a spectralon-coated hemispherical/baffle light 131 source of $30 \mathrm{~W}$ tungsten and halogen light bulbs was set at a 45 degree angle $50 \mathrm{~cm}$ from the 132 sample (Rock et al. 1994). Distance from the optical lens of the spectrometer to the sample was $13350 \mathrm{~cm}$ yielding a field of view of approximately $7 \mathrm{~cm}^{2}$. The spectrometer measured reflectance 134 from 400 to 1000 nanometers in approximately $2 \mathrm{~nm}$ steps, and from 1000 to $2500 \mathrm{~nm}$ in 135 approximately $12 \mathrm{~nm}$ steps. Visible light reflectance was measured from 400 to $680 \mathrm{~nm}$, NIR 136 reflectance from 750 to $1400 \mathrm{~nm}$, and middle infrared reflectance (MidIR) from 1400 to $2500 \mathrm{~nm}$ 137 (Gates et al. 1965, Gausman 1977). The red edge spectral region was defined as 680 to $750 \mathrm{~nm}$ 138 (Horler et al. 1983). Each sample was scanned three times with a 90 degree rotation in between 139 measurements. The three scans were averaged; estimated Landsat Thematic Mapper (TM) band 140 values and VIs were calculated and tabulated using ProVIRIS Software (Shannon Spencer, 141 Copyright 2000). Vegetation indices of immediate interest were the REIP, NDVI, MSI, and NIR 3/1 ratio. 143 The REIP, an estimator of chlorophyll content, was determined as the wavelength at which the 144 first derivative curve between 680 and $750 \mathrm{~nm}$ reached its maximum peak (Horler et al. 1983). 145 The NDVI, an estimator of canopy biomass and leaf chlorophyll content, was calculated using 
146 estimated Landsat red (B3) and NIR (B4) bands (B4 - B3/B4 + B3) (Rouse et al. 1974). The

147 MSI, an estimator of foliar water content, was calculated using estimated Landsat NIR and

148 MidIR (B5) bands (B5/B4) (Rock et al. 1986). The NIR 3/1 ratio, an estimator of foliar

149 maturity, was calculated as the slope of the NIR plateau (Bubier et al. 1997). Indices and spectra

150 data from all sites were pooled by infestation status (infested or non-infested) and then averaged

151 for each month; any non-infested samples from trees that were later determined to be infested

152 were excluded. Site to site variation in the 2012 data was not specifically addressed due to the

153 majority (79.7\%) of infested samples coming from the Rachael Carson National Wildlife Refuge.

154 Statistical differences between infested and non-infested foliage were tested for both the spectra

155 and the VIs using Wilcoxon's Tests in JMP (JMP Pro Version 10.0. SAS Institute Inc., Cary,

156 NC, 1989-2007). Reflectance difference (infested minus non-infested) and sensitivity

157 (reflectance difference divided by non-infested) curves were used to highlight portions of the

158 hemlock reflectance spectrum most affected by HWA infestation (Carter 1993).

\subsection{Reflectance and Spectral Health Indices}

In 2013, only trees at the Massabesic Experimental Forest were sampled. Sampling in

2013 was reduced to one site in order to limit differences between sites as a possible

confounding factor from 2012 data. In addition, sampling began two weeks prior to HWA

163 emergence allowing us to observe infestation impacts before and after HWA settlement on first

164 year growth. Five non-infested and five HWA infested hemlock of similar DBH $(51.5 \pm 9.8 \mathrm{~cm})$

165 were selected. Sunlit terminal branches of each hemlock were sampled over a five week period

166 from 4 June to 1 July using pole pruners or a 12-guage shotgun with steel shot. Only foliage not

167 impacted by the shot was used. Following transport to the lab foliar fluorescence measurements

168 were taken. 
After the fluorescence measurements were conducted, reflectance measurements and

170 statistical analysis of first year foliage were performed using the same protocols described for the

1712012 sampling period. Following reflectance measurements the very top layer of foliage was

172 used for pigment extraction; only the top layer was used in an effort to limit variation in

173 correlating VIs with chlorophyll concentrations. Linear regression was performed in JMP 10.0

174 with total chlorophyll as the independent variable and the REIP and NDVI values as the 175 dependent variables.

\subsection{Chlorophyll Extraction and Fluorescence}

Following the 2012 sampling period frozen foliage from June, July and August were used

178 in pigment extractions. For each tree needle year, approximately $0.5 \mathrm{~g}$ of needle material was

179 scissors chopped into a petri dish and homogenized. Approximately $0.1 \mathrm{~g}$ of the needle mixture was placed into a centrifuge tube with $10 \mathrm{~mL}$ of $95 \%$ ethyl alcohol (ETOH) and incubated in a

$18160^{\circ} \mathrm{C}$ water bath for 16 hours (Minocha et al. 2009). Extractions were cooled to room

182 temperature in the dark and transported to a separate lab in a cooler. Samples were centrifuged

183 for five minutes at 5000 revolutions per minute (RPM). Approximately $2 \mathrm{~mL}$ of extract were 184 pipetted into $3 \mathrm{~mL}$ quartz cuvettes ( $n=5$ for each tube); absorbance was measured using a 185 Genesys 6 (Fisher Scientific) spectrophotometer at 470, 649, and $664 \mathrm{~nm}$. Chlorophylls $(a, b$ 186 and total) and total carotenoid concentrations were calculated using equations from Lichtenthaler 187 (1987). Pigment extraction protocols for the 2013 samples were slightly different.

188 Approximately $0.05 \mathrm{~g}$ of fresh needle material per sample was scissors chopped into each of two 189 centrifuge tubes and frozen immediately following reflectance measurements. Extractions took 190 place in July 2013. Tubes were pulled from the freezer and $5 \mathrm{~mL}$ of ETOH was added;

191 approximately $2 \mathrm{~mL}$ of extract were pipetted into $3 \mathrm{~mL}$ quartz cuvettes $(n=2$ for each tube). 
192 Absorbance measurements and pigment concentration calculations followed the same protocols 193 as the 2012 samples.

Prior to fluorescence measurement five clips (per sample) were attached to infestation

195 intensity representative needles for a 20 minute dark adaptation period; fluorescence

196 measurements were taken within 4 hours of branches being removed from the tree. The Handy

197 PEA Fluorimeter (Hansatech Instruments Limited; Norfolk, UK) measured fluorescence induced

198 in a $12.6 \mathrm{~mm}^{2}$ area by exposing it to a saturating red actinic light intensity of $1500 \mu \mathrm{Mol} \mathrm{m}^{-2} \mathrm{~s}^{-1}$

199 for a duration of 1 second. Fluorimeters such as the Handy PEA measure the polyphasic rise in

200 chlorophyll fluorescence of photosystem II (PSII), providing quantitative and qualitative

201 interpretations of active processes within the photosynthetic apparatus. Fluorescence intensity

202 measurements were used in the multiparametric JIP Test (Strasser et al. 2000, 2004). Statistical

203 differences in parameters were analyzed using Wilcoxon's Tests in JMP 10.0; here we report

204 only on parameters Fv/Fm which is the maximum quantum efficiency of PSII; the Absorbance

205 Performance Index (PIabs) which is a measure of plant vitality that examines the quantity of

206 reaction centers, the maximum energy flux that reaches the reaction centers of PSII, and electron

207 transport; and the Total Performance Index (PItot) which extends the PIabs parameter to include

208 reductions at the electron acceptor site of PSI (Perboni et al. 2012).

\subsection{Fresh and Dry Weight}

After fluorescence and reflectance measurements were taken, and the top foliage reserved

211 for pigment extraction, fresh weight of the sample was measured. Twigs with attached foliage

212 were then dried at 50 degrees Celsius for seven days in a brown paper bag. Dry weight for the

213 sample was then recorded. Differences in foliar moisture content (fresh weight minus dry 
214 weight) were analyzed using Wilcoxon's Tests in JMP 10.0. Correlation of foliar moisture 215 content to the MSI was calculated in JMP 10.0.

216 3. Results

217

\subsection{Defoliation Ratings}

Hemlocks at the Massabesic Experimental Forest had an average defoliation rating of $1.58 \pm 0.68(N=93)$. Of first year foliage sampled from 25 hemlock crowns, $24.6 \%$ were infested with HWA (Table 2). Hemlocks at the Rachael Carson Wildlife Reserve had an average defoliation rating of $1.14 \pm 0.43(N=63)$. Of the first year growth sampled from 23 hemlock crowns, 96.9\% were infested with HWA (Table 2). At the Russell-Abbott State Forest the average hemlock defoliation rating was $1.33 \pm 0.94(N=82)$. Of the first year growth sampled

224 from 24 trees, 4.5\% were infested with HWA (Table 2). At Northwood Meadows State Park 225 HWA all samples from 23 trees were not infested with HWA (Table 2). The average hemlock 226 defoliation rating was $1.21 \pm 0.73(N=210)$.

\subsection{Reflectance and Spectral Health Indices}

Reflectance values of first year infested foliage were consistently lower than non-infested foliage in the visible $(400-680 \mathrm{~nm})$ and red edge $(680-750 \mathrm{~nm})$ portions of the spectrum during the seven month sampling period. Differences in visible light reflectance were greatest near the green peak $(\sim 550 \mathrm{~nm})$. Infested foliage green peak values ranged from 0.1 to $2.5 \%$ lower than non-infested foliage; the greatest differences occurred in June (2.6\%) and July $(2.0 \%)$ post HWA settlement (Fig. 2A, 2C). Infested foliage red edge $(680-750 \mathrm{~nm})$ reflectance values ranged from 0.8 to $4.6 \%$ lower than non-infested foliage, indicating a shift of the red edge to longer 
236 July (3.5\%) (Fig. 2A, 2C). For the remaining months green peak differences were less than $1.3 \%$

237 and red edge differences were less than $2.4 \%$.

238

239

240

241

242

243

244

245

246

247

248

249

250

251

252

253

254

255

256

257

258

Statistical differences between current year infested and non-infested foliage in the visible and red edge regions were most notable in June and July (Fig. 3A, 3C). In June, 28 bands from 400 to $494 \mathrm{~nm}, 32$ bands from 500 to $547 \mathrm{~nm}$, and 21 bands from 648 to $679 \mathrm{~nm}$ comprised the 81 total bands across the visible portion of the spectrum that were significantly different $(P<$ 0.05) (Table 3). The most significant $(P<0.01)$ bands in the visible region were at 493 and 502 nm. In the red edge region 37 bands were found to be significantly different $(P<0.05)$ (Table 3). The most significant $(P<0.01)$ bands were from 721 to $729 \mathrm{~nm}$; six consecutive bands that were each approximately $2 \mathrm{~nm}$ wide. In July, 50 bands from 500 to $596 \mathrm{~nm}$ and 7 bands from $604-635 \mathrm{~nm}$ comprised the 57 total bands across the visible portion of the spectrum that were significantly different $(P<0.05)$ (Table 3$)$. The most significant $(P<0.01)$ bands in the visible region were at 520,525 , and $543 \mathrm{~nm}$. Only one band in the red edge at 705 was found to be significantly different $(P=0.04)$.

Differences in NIR reflectance $(750$ - $1400 \mathrm{~nm})$ ranged from 3.0\% lower than noninfested foliage in June (Fig. 2A) to 2.0\% higher than non-infested foliage in September, October and November (Fig. 2G, 2I, 2K). No statistical differences between infested and non-infested foliage in the NIR region were observed (Table 3) (Fig. 3). Differences in MidIR reflectance (1400 - $2400 \mathrm{~nm}$ ) values ranged from 1.8\% lower than non-infested foliage in October (Fig. 2G) to $0.1 \%$ higher than non-infested foliage in December (Fig. $2 \mathrm{~K})$. Statistical differences $(P<$ 0.05) between infested and non-infested foliage in the MidIR region occurred in July (2049, 2293, 2305, and $2364 \mathrm{~nm}$ ), August (2434 nm), October (2305 nm), November (2281 nm), and December (2329 and $2446 \mathrm{~nm}$ ) (Table 3) (Fig. 3C, 3E, 3I, 3K, 3M). 
Sensitivity to infestation (reflectance difference divided by non-infested reflectance; Fig.

260

261

262

263

264

265

266

267

268

269

270

271

272

273

274

275

276

277

278

279

280

281

2) of first year foliage was greatest in both the visible and red edge spectral regions for all months observed except for October (Fig. 2J) when the MidIR reflectance region had the greatest sensitivity. The greatest sensitivity to infestation for first year growth was observed in late June and July. In the visible light reflectance region, sensitivity in June and July was greatest from approximately 500 to $650 \mathrm{~nm}$ (Fig. 2B, 2D). In the red edge region, sensitivity was greatest at approximately $700 \mathrm{~nm}$ (Fig. 2B, 2D).

Second year foliage reflectance difference values were inconsistent compared to current year reflectance differences. Differences in visible light reflectance were greatest near the green peak; values ranged from $0.4 \%$ lower than non-infested foliage in June (Fig. 4A) to $0.3 \%$ higher in October (Fig. 4I). Red edge spectral region values ranged from 2.2\% lower than non-infested foliage in September to $2.7 \%$ higher in July (Fig. 4A, 4C). Differences in NIR reflectance ranged from 2.6\% lower than non-infested foliage in September to 3.1\% higher in July (Fig. 4C, 4G). Middle infrared reflectance values of infested foliage were consistently lower than noninfested foliage from June through November (Fig. 4A, 4C, 4E, 4G, 4I, 4K) and difference values ranged from 2.3\% lower in September (Fig. 4G) to 1.7\% higher in December (Fig. 4M).

Statistical differences between second year infested and non-infested foliage were greatest in the visible spectral region in July (Fig. 3D). In July, 13 bands from 400 to $494 \mathrm{~nm}$ and 5 consecutive bands from 503 to $515 \mathrm{~nm}$ comprised the 18 total bands across the visible portion of the spectrum that were statistically significant $(P<0.05)$ (Table 3$)$. The only band in the red edge region that was significantly different was at 687 in August $(P=0.03)$ (Fig. 3F). In the NIR region three consecutive significantly different bands were observed in November $(1369,1383$, and 1397) (Fig. 3L); two of those bands were also significantly different in 
282 December $(1383$ and 1397) $(P<0.05)($ Fig 3N). More notable was the number of significantly 283 different bands in the MidIR spectral region in November (26 bands from 1411 to $2305 \mathrm{~nm}$ ) ) 284 (Fig. 3L) and December (37 bands from 1411 to $2411 \mathrm{~nm})($ Fig 3N) $(P<0.05)$ (Table 3$)$. Sensitivity to infestation of second year foliage in the visible and red edge spectral

286

287 288 289 290 291 293 294 295 296 297 298 299 300 301 302 303

Mean REIPs of first year infested foliage were consistently higher than non-infested foliage over the sampling period (Fig. 5A). Mean REIPs of first year foliage were statistically greater only in December $(P=0.04)$ (Table 4). Second year growth mean REIPs for infested foliage were not statistically different from non-infested foliage (Fig. 5B). Like the REIP, mean NDVI values for first year infested foliage were generally higher than non-infested foliage (Fig. 5C), but were never statistically different. No significant differences in mean NDVI values for second year infested foliage were observed (Table 4).

Both first year and second year infested foliage generally had lower mean MSI values than non-infested foliage (Fig. 5E, 5F). First year foliage was found to have statistically lower mean MSI values in October $(P=0.01)$ and November $(P=0.02)$ (Table 4). Second year infested foliage had statistically lower mean MSI values in July $(P=0.03)$, October $(P=0.03)$, and November $(P=0.03)$ (Table 4$)$. 
ratio values compared to non-infested foliage (Fig. 5G, 5H). First year foliage had statistically

lower NIR 3/1 values in October $(P=0.01)$ and November $(P=0.02)$ (Table 2). Mean June NIR

3/1 ratio values for second year foliage were not statistically different (Fig. 5H). Mean NIR 3/1

ratio values for second year foliage were statistically lower than non-infested foliage the months

of August $(P=0.03)$, October $(P=0.01)$, and November $(P=0.02)$ (Table 2$)$.

\subsection{Reflectance and Spectral Health Indices}

Hemlock woolly adelgids began to emerge at Massabesic Experimental Forest the week

of 10 June, and by 17 June HWA crawlers were present on first year growth of infested trees.

313 Improper sampling the week of 24 June resulted in only three samples of infested first year

314 growth. Infested foliage had consistently lower visible and red edge reflectance values than non315 infested foliage; the greatest differences occurred the week of 1 July (Fig. 6I) two weeks after 316 HWA settlement. Differences in green peak reflectance values ranged from $2.9 \%$ lower than 317 non-infested foliage on 1 July (Fig. 6I) to 1.0\% higher on 17 June (Fig. 6E). Differences in red 318 edge region reflectance values ranged from 3.8\% lower than non-infested foliage on 1 July (Fig. 6I) to $0.2 \%$ higher on 24 June (Fig. 6G). Differences in NIR reflectance values ranged from $3.0 \%$ lower than non-infested foliage on 10 June (Fig. 6C) to $12.1 \%$ higher on 24 June (Fig. 6G).

321 Differences in MidIR reflectance values ranged from 2.5\% lower than non-infested foliage on 10 322 June (Fig. 6C) to $2.5 \%$ higher on 4 June (Fig. 6A). 
326 0.05) (Table 5) (Fig. 7E). In the red edge region, 12 significantly different bands were observed

327 from $691-714 \mathrm{~nm}(P<0.05)$. Four bands in the MidIR region $(2305,2364,2388$, and 2481$)$

328 were also significantly different $(P<0.05)$ (Table 5) (Fig. 7E). Significant differences were also

329 observed the week of 17 June in the NIR spectral region, in all twenty-eight bands from 961 to

$3301311 \mathrm{~nm}$ were significantly greater than non-infested foliage $(P<0.05)$ (Table 5) (Fig. 7C).

331

332

333

334

335

336

337

338

339

340

341

342

343

344

345

346

347

Sensitivity to infestation was greatest in both the visible and red edge spectral regions the week of 1 July, approximately two weeks after HWA settlement on new hemlock growth. Sensitivity in the visible portion of the spectrum was greatest from 515 to $637 \mathrm{~nm}$ (Fig. 6J), and in the red edge region sensitivity peaked at approximately $700 \mathrm{~nm}$. In the NIR and MidIR spectral regions sensitivity was greatest the week of 24 June.

Infested foliage generally had higher mean REIP and NDVI values over the five week sampling period (Fig. 8A, 8B). Statistically greater mean REIP values were observed on 1 July $(P=0.01)$ (Table 6). Statistically greater mean NDVI values were observed on 4 June $(P=0.02)$ and 1 July $(P=0.02)$ (Table 6). Moisture Stress Index (MSI) and NIR 3/1 values were not statistically different between infested and non-infested foliage (Table 6) (Fig. 8C, 8D).

\subsection{Chlorophyll Extraction and Fluorescence}

First year growth of infested trees in 2012 generally had higher mean concentrations of all measured pigments than non-infested trees, but significantly greater concentrations were not observed (Table 7). Photosynthetic pigment values in second year growth also did not differ between infested and non-infested foliage (Table 7).

First year growth of infested trees in 2013 from the Massabesic Experimental Forest generally had higher mean concentrations of all measured pigments than non-infested trees, 
348 although not always statistically greater (Fig. 9). Statistically greater concentrations of 349 chlorophyll $a$ were observed on 4 June $(P=0.04)$ and 1 July $(P=0.02)$, and chlorophyll $b$ on 17 350 June $(P=0.05)$ (Table 8$)$. Statistically greater concentrations of total carotenoids was observed 351 on 4 June $(P=0.01)$ and 24 June $(P=0.04)$ (Table 8$)$. Total chlorophyll was not statistically

352 different between infested and non-infested foliage. Total chlorophyll concentration had a 353 positive linear relationship to the REIP $\left(r^{2}=0.81, \mathrm{df}=1,48, F=204.95, P<.0001\right)$; the natural $354 \log$ of total chlorophyll was positively related to the NDVI $\left(r^{2}=0.89\right.$, $\mathrm{df}=1,48, F=469.25, P<$ $355.0001)$.

Infested hemlock foliage showed no statistical differences in Fv/Fm compared with non357 infested foliage over the five week sampling period (Fig. 9C) (Table 9). Statistically greater 358 PIabs for infested foliage was observed on 4 June $(P=0.05), 24$ June $(P=0.01)$ and 1 July $(P=$ 359 0.0002) (Fig. 10B) (Table 9). Infested foliage also had statistically greater PItot the weeks of 4 360 June $(P=0.02), 10$ June $(P=0.006), 24$ June $(P=0.004)$ and 1 July $(P<0.0001)$ (Fig. 10A) 361 (Table 9).

\subsection{Fresh and Dry Weight}

Moisture content (fresh weight minus dry weight) of infested foliage did not differ statistically from non-infested foliage (Fig. 11A). The MSI was found to be negatively correlated with needle moisture content values $(r=-0.43, P=0.002)$ (Fig. 11B).

\section{Discussion}

Although past studies using Landsat TM data, VIs, and transformations to map highseverity HWA-induced defoliation have been successful (Bonneau et al. 1999, Royle \& Lathrop 369 2002), currently, those approaches may not be suitable for these study areas. Among the four 
370 sites mean defoliation was less than $26 \%$ regardless of HWA presence. The Rachael Carson

371 Wildlife Refuge was the oldest reported infestation and the most heavily infested; however, it

372 was also the least defoliated based on field ratings $(1.14 \pm 0.43)$. The Massabesic Experimental

373 Forest plot, although being newly infested, had the highest defoliation average of $1.58( \pm 0.68)$.

374 To conclude that no relationship between infestation intensity and defoliation existed based on

375 four sites would be presumptuous; however, hemlock defoliation and mortality as seen in the

376 Mid-Atlantic and southern New England states had not yet occurred at these site locations.

378 infestation may be partially explained by site geographic location. Orwig et al. (2012) found that

379 the severity of damage caused by HWA was negatively correlated with latitude; however,

380 damage could be exacerbated by drought and site exposure conditions. The latitude damage

381 gradient is in part due to cold winter temperatures which causes HWA mortality, upwards of

$38290 \%$ locally (Trotter and Shields 2009), thereby retarding HWA population growth in newly

383 infested stands and extending the timeframe to significant defoliation and mortality. These semi-

384 annual reductions in HWA populations in concert with site characteristics favorable to hemlock

385 also induce year to year cycles of hemlock recovery and decline in chronically infested stands

386 (Mayer et al. 2002). Regardless of annual fluctuations in winter temperatures positively or

387 negatively influencing HWA populations and cycles of hemlock decline and recovery,

388 significant defoliation in this region had been limited as of 2014 and therefore changes in

389 biomass values alone may not be adequate in detecting early infestation symptoms.

391 HWA emergence) may be the optimal time of year to discriminate between HWA infested and 392 non-infested forests with reflectance measuring sensors. Reflectance difference and sensitivity 
393

394

395

396

397

398

399

400

401

402

403

404

405

406

407

408

409

410

411

412

413

414

415

curves of first year foliage from both 2012 and 2013 indicated that the visible and red edge spectral region reflectance values of infested foliage were consistently lower than non-infested foliage during that time period, and that those spectral regions would be the most sensitive in detecting infestation. Statistically lower reflectance values were observed across multiple bands in the visible and red edge spectral regions. In June and July of 2012 a combined 118 different bands from $400-680 \mathrm{~nm}(\sim 2 \mathrm{~nm}$ bandwidths), and 37 different bands from $680-736 \mathrm{~nm}$ along the red edge ( $\sim 2 \mathrm{~nm}$ bandwidths), were found to be significantly different between infested and non-infested foliage. A similar pattern was observed the week of 1 July in 2013 when 44 bands in the visible and 12 bands in the red edge spectral regions were significantly different. Additionally, second year infested foliage in July of 2012 had significantly lower reflectance values at 18 different bands from $400-515 \mathrm{~nm}$. These observations agree with numerous other studies that have shown that the visible and red edge regions of the reflectance spectrum are the most affected by and sensitive to plant stress due to changes in foliar pigment concentrations (Carter 1993, Carter \& Knapp 2001, Gitelson et al. 1996, Rock et al.1988). However, considering that forest canopy remote sensing data typically consists of mixed pixels containing multiple trees (and tree species), layers of foliage, foliage growth years and woody material, the significance of the spectral differences observed in the data may be subdued at moderate and low spatial resolutions.

The patterns observed in the current year foliage reflectance data correspond well with the sisten crawler and aestivation (summer dormancy) phases of the HWA lifecycle. Hemlock woolly adelgids have two generations per year, the progrediens which hatch in March and the sistens which hatch in June (for a detailed study of the HWA lifecycle see McClure and Cheah 1999). Our data cover the majority of the sisten generation. The greatest observed differences in 
416 reflectance occurred in late June and July in the weeks following the emergence of sisten HWA

417 crawlers and their settlement at the base of new growth. During that time significantly lower

418 visible spectral reflectance, shifts of the red edge to longer wavelengths, and lower MidIR

419 reflectance were observed. In August, when the HWA nymph is reported to begin aestivation

420 and feeding pauses until October, differences in the visible and red edge regions reduced

421 substantially before rebounding in November and December when adelgid feeding and growth

422 resumed. It is not clear whether the physiological and spectral responses were driven by HWA

423 influencing source-sink dynamics within the tree (Gómez et al. 2012) or were induced by

424 enzymes released by the HWA (Oten et al. 2014).

The aestivation period was also characterized by greater NIR reflectance from infested

426 foliage August through November. Leaf reflection in the NIR spectral region is due to light

427 refraction at cell wall and intercellular air space interfaces (Gates et al. 1965); generally, higher

428 NIR reflectance is associated with healthier vegetation and older conifer needle years (Rock et

429 al. 1994). The reasons why NIR reflectance of current year infested foliage jumped from being 430 approximately $3 \%$ lower than non-infested foliage in July, to approximately $2 \%$ higher than non-

431 infested foliage in November, and finally no different from non-infested foliage in December,

432 remain unclear without leaf anatomical evaluation. However, it is possible that the lapse in

433 HWA feeding resulted in a period of rapid growth and expansion of intercellular airspaces,

434 thereby increasing NIR reflectance.

Patterns in the second year foliage reflectance data did not correspond as well with the

436 HWA lifecycle. The reason for this was unknown, although chronic infestation and its effects on

437 foliar metabolism may explain the month to month variability in reflectance values. Significant

438 differences in reflectance in the visible, red edge and MidIR portions of the spectrum were 
439 observed before and after aestivation. Before aestivation, significant differences in the visible 440 and red edge spectral regions occurred in July and August; perhaps a delayed response to sisten 441 HWA feeding on the newer foliage. After aestivation, significant differences were observed in 442 the MidIR spectral region in November and December, signaling changes in foliar moisture 443 content. The data indicated that although the REIP may be highly correlated to needle chlorophyll 445 content, use of the REIP alone in detecting HWA infestations may not be suitable because 446 differences in chlorophyll content between newly infested and non-infested trees may not be 447 significant or consistent, because of differences in recovery and decline cycles at chronically 448 infested sites, and because other wavelengths along the red edge may be more sensitive. For 449 example, in June 37 consecutive bands along the red edge from 680 to $736 \mathrm{~nm}$ were significantly 450 different between infested and non-infested foliage including the wavelength at which their 451 respective REIPs occurred $(718 \mathrm{~nm})$; however, there were no significant differences in 452 chlorophyll content or REIP. This is because a significant difference in percent reflectance at the 453 wavelength at which the REIP occurs does not translate into significantly different REIPs; the 454 two measurements are mutually exclusive. In addition there were six bands from $721-729 \mathrm{~nm}$ 455 where the greatest statistical differences in the red edge occurred, that likely would have been 456 more important than the REIP in detecting infested hemlock. Therefore, in choosing the 457 appropriate sensor for detecting HWA infestations, a sensor with wider $(>2 \mathrm{~nm})$ bands along the 458 red edge may be just as useful as a sensor with very narrow $(\leq 2 \mathrm{~nm})$ bands from which the REIP 459 can be determined. 
462 initially greater than non-infested needles in June 2012. However, first year needles had

463 statistically lower mean NIR 3/1 ratio values in October and November, and second year needles

464 had statistically lower mean NIR 3/1 ratio values in August, October and November. The 2013

465 NIR 3/1 ratio values exhibited a similar short term pattern. Mean NIR 3/1 ratio values were

466 greater in the first sampling week but lower in the remaining four sampling weeks, although

467 never statistically significant. These patterns indicated that infested hemlock needles may have

468 had a more difficult time reaching the same cellular and structural maturity of non-infested

469 hemlock needles; however, anatomical data would be needed to reach definitive conclusions. In

470 addition, a possible confounding link between the NIR 3/1 ratio and leaf turgidity cannot be

471 ignored as the patterns in the MSI and NIR 3/1 indices were similar (Hunt and Rock 1989).

473 MSI values) than non-infested foliage over the seven month period. Significantly lower MSI

474 values were observed in October and November for both current year and second year foliage

475 which corresponds with HWA breaking aestivation. However, only a moderate correlation $(r=-$

476 0.43) of the MSI to needle moisture content was observed. This indicated that although the MSI

477 may have had some usefulness in discriminating between infested and non-infested hemlock

478 foliage, it was not a highly accurate gauge of needle turgidity. Regarding the remote sensing of

479 hemlock canopies, the supposed increase in turgidity and differences in MSI values that were

480 observed between infested foliage and non-infested foliage may not extend to sub-mesic sites

481 where water availability is low or to chronically infested sites during decline cycles.

483 long term; however, our data suggest a possible compensatory increase in photosynthetic

484 machinery and function in new growth during the early stages of infestation. This increase was 
485 observed through both direct and indirect chlorophyll measurements. Increased chlorophyll 486 content was directly measured through pigment extraction and determination of concentration 487 through well-established methods (see Lichtenthaler 1987, Minocha et al. 2009). Indirect 488 measurements of increased chlorophyll concentration and function were accomplished through 489 VIs (REIP and NDVI) and fluorescence measurements. Both pigment extraction and reflectance 490 measurements of infested foliage had consistently higher mean chlorophyll concentrations, some 491 of which means were significantly greater than non-infested foliage. In addition, fluorescence 492 measurements indicated that the chlorophyll in infested foliage was functioning properly $493(\mathrm{Fv} / \mathrm{Fm})$, and that infested foliage was absorbing more photon energy (PIabs) than non-infested 494 foliage due to increased chlorophyll concentrations, resulting in greater overall photosynthetic 495 capability (PItot) in terms of machinery.

The increase in photosystem capability in HWA infested hemlock, as indicated through

497 the pigment extraction, reflectance and fluorescence data, may be the result of several factors.

498 First, Gómez et al. (2012) documented that after the first year of HWA infestation total amino 499 acid concentration in new un-infested foliage was $330 \%$ greater than in the control treatment. 500 Whether the increase in free amino acids was either a manipulation of the host species by HWA 501 or a systemic compensatory response whereby $\mathrm{N}$ was reallocated from stressed to non-stressed 502 foliage was unknown; regardless, our data suggests that an increase in $\mathrm{N}$ may have resulted in 503 greater concentrations of chlorophyll. Second, water stress in plants has been shown to increase 504 foliar N availability and decrease photosynthetic capacity. Gonda-King et al. (2014) reported 505 that HWA infested hemlock seedlings (<3ys age) had greater negative water potential (i.e. were 506 water stressed) resulting in greater total $\mathrm{N}$ content, decreased stomatal conductance, and 507 decreased net photosynthesis in a controlled experiment. Our MSI data from mature hemlocks 
508 indicated that infested foliage was less water stressed than non-infested foliage and that water

509 was likely not a limiting factor for photosynthesis. Although it was possible that the

510 combination of greater availability of nitrogen and water produced a temporary increase in

511 photosystem machinery and function in the new flush of foliage, stomatal conductance was not

512 measured and therefore we cannot state with certainty that the increased photosynthetic

513 machinery resulted in greater photosynthetic rates (Rubino et al. 2015).

\section{5. Conclusion}

Sensor selection and timing of remote sensing data collection are important aspects of project planning. To discriminate between incipient HWA infested and non-infested hemlock

517 stands aerial spectrometers measuring reflectance in the visible and red edge spectral regions

518 over narrow bandwidths $(\sim 2 \mathrm{~nm})$ would be best; however, aerial and satellite multispectral

519 sensors with wider bandwidths may be sufficient. Perhaps more importantly, our data suggest

520 that projects involving on-demand aerial data collection should time collection efforts in the

521 weeks immediately following sisten adelgid emergence in June; projects that involve gathering

522 of previously acquired satellite data should focus on late June or July. Acquiring data outside of

523 this window may reduce the likelihood of successful discrimination between infested and non-

524 infested hemlock stands.

These recommendations are based on the reflectance data which showed that in late June

526 and early July infested foliage were most significantly different from non-infested foliage in the

527 visible and red edge spectral regions. These peaks in spectral differences constitute peaks in

528 sensitivity, the ability of the sensor to distinguish between infested and non-infested hemlock

529 forests. In all 118 different wavelengths in the visible spectral region and 37 different 
530 wavelengths along the red edge were observed to be significantly different. The high number of

531 significantly different wavelengths indicated that sensors measuring in either narrow

532 (hyperspectral) or wide band widths (i.e. aerial and satellite multispectral data) in the visible and

533 red edge wavelengths may have the ability to detect early infestations. Our data also suggest that

534 wavelengths or indices that correlate with leaf turgidity and chlorophyll content may be useful in

535 discriminating between HWA infested and non-infested forests. Infested foliage was found to

536 have contained greater concentrations of both chlorophyll and moisture, although the differences

537 were not always statistically significant. Furthermore, our data support the view of a

538 compensatory response to initial infestation in current year foliage, although the mechanism

539 triggering this response was unclear. 
540 Acknowledgements: This research was a portion of a thesis submitted to the Graduate School

541 of the University of New Hampshire as part of the degree requirements of a Master's of Science

542 in Natural Resources. Funding for this project was provided through the United States

543 Department of Agriculture Forest Service (Forest Health and Protection), New Hampshire Space

544 Grant Consortium, University of New Hampshire Farrington Fund Fellowship and College

545 Woods Scholarship, and the Bearcamp Valley Garden Club Scholarship. Marc DiGirolomo, 546 Angela Hammond, Michael Simmons, Michael Bohne, Robert Cooke, Edward Jordan, Kevin

547 Dodds, and Garret Dubois of the USFS provided field support. We would also like to thank

548 David Orwig for his comments on an earlier version of this manuscript, and the anonymous

549 reviewers for their comments and suggestions. 


\section{References:}

Bonneau, L. R., Shields, K. S., and Civco, D. L. 1999. Using satellite images to classify and analyze the health of hemlock forests infested by the hemlock woolly adelgid. Biol. Invasions 1: 255-267.

Bubier, J. L., Rock, B. N., and Crill, P. M. 1997. Spectral Reflectance Measurements of Boreal Wetland and Forest Mosses. J. Geophys. Res. 102(D24): 29,483-29,494.

Carter, G. A. 1993. Responses of Leaf Spectral Reflectance to Plant Stress. Bot. Soc. Am. 80(3): 239-243.

Carter, G. A., and Knapp, A. K. 2001. Leaf Optical Properties in Higher Plants : Linking Spectral Characteristics to Stress and Chlorophyll Concentration. Bot. Soc. Am. 88(4): 677-684.

Davis, D. D., Fromm, M. S., and Davis, M. D. 2007. Impact of the Hemlock Woolly Adelgid on Radial Growth of Eastern Hemlock in Pennsylvania. pp. 157-162 Proceedings of the 15th Central Hardwood Forest Conference. USDA Forest Service, Gen. Tech. Rep. SRS-101.

Domec, J.-C., Rivera, L. N., King, J. S., Peszlen, I., Hain, F., Smith, B., and Frampton, J. 2013. Hemlock woolly adelgid (Adelges tsugae) infestation affects water and carbon relations of eastern hemlock (Tsuga canadensis) and Carolina hemlock (Tsuga caroliniana). New Phytol. 199(2): 452-63. doi:10.1111/nph.12263.

Ellison, A. M., Bank, M. S., Clinton, B. D., Colburn, E. A., Elliott, K., Ford, C. R., Foster, D. R., Kloeppel, B. D., Knoepp, J. D., Lovett, G. M., Mohan, J., Orwig, D. A., Rodenhouse, N. L., Sobczak, W. V., Stinson, K. A., Stone, J. K., Swan, C. M., Thompson, J., Von Holle, B., and Webster, J. R. 2005. Loss of Foundation Species: Consequences for the Structure and Dynamics of Forested Ecosystems. Front. Ecol. Environ. 3(9): 479-486.

Gates, D. M., Keegan, H. J., Schleter, J. C., and Weidner, V. R. 1965. Spectral Properties of Plants. Appl. Opt. 4(1): 11-20.

Gausman, H. W. 1977. Reflectance of leaf components. Remote Sens. Environ. 6(1): 1-9. doi:10.1016/0034-4257(77)90015-3.

Gitelson, A. A., Merzlyak, M. N., and Lichtenthaler, H. K. 1996. Detection of Red Edge Position and Chlorophyll Content by Reflectance Measurements Near $700 \mathrm{~nm}$. J. Plant Physiol. 148: 501-508. doi:10.1016/S0176-1617(96)80285-9.

Gómez, S., Orians, C. M., and Preisser, E. L. 2012. Exotic herbivores on a shared native host: tissue quality after individual, simultaneous, and sequential attack. Oecologia 169(4): 101524. doi:10.1007/s00442-012-2267-2. 
Gonda-King, L., Gómez, S., Martin, J. L., Orians, C. M., and Preisser, E. L. 2014. Tree responses to an invasive sap-feeding insect. Plant Ecol. 215(3): 297-304. doi:10.1007/s11258-014-0298-y.

Hanavan, R. P., Pontius, J., and Hallett, R. 2015. A 10-Year Assessment of Hemlock Decline in the Catskill Mountain Region of New York State Using Hyperspectral Remote Sensing Techniques. J. Econ. Entomol.: 1-11. doi:10.1093/jee/tou015.

Horler, D. N. H., Dockray, M., Barringerj, A. R., and Barber, J. 1983. Red Edge Measurements for Remotely Sensing Plant Chlorophyll Content. Plant Physiol. 3: 273-277.

Hunt, E. R., and Rock, B. N. 1989. Detection of Changes in Leaf Water Content Using Near- and Middle-Infrared Reflectances. Remote Sens. Environ. 30: 43-54.

Lichtenthaler, H. K. 1987. Chlorophylls and Carotenoids: Pigments of Photosynthetic Biomembranes. pp. 350-382 in L. Packer and R. Douce, editors. Methods in Enzymology. Academic Press, Inc.

Mayer, M., Chianese, R., Scudder, T., White, J., Vongpaseuth, K., and Ward, R. 2002. Thirteen Years of Monitoring the Hemlock Woolly Adelgid in New Jersey Forests. pp. 50-60 Hemlock Woolly Adelgid in the Eastern United States Symposium.

McClure, M. S. 1987. Biology and Control of Hemlock Woolly Adelgid, Bulletin 851. New Haven, CT.

McClure, M. S., and Cheah, C. A. S.-J. 1999. Reshaping the ecology of invading populations of hemlock woolly adelgid, Adelges tsugae (Homoptera : Adelgidae), in eastern North America. Biol. Invasions(1): 247-254.

Miller-Pierce, M. R., Orwig, D. A., and Preisser, E. 2010. Effects of hemlock woolly adelgid and elongate hemlock scale on eastern hemlock growth and foliar chemistry. Environ. Entomol. 39(2): 513-9. doi:10.1603/EN09298.

Minocha, R., Martinez, G., Lyons, B., and Long, S. 2009. Development of a standardized methodology for quantifying total chlorophyll and carotenoids from foliage of hardwood and conifer tree species. Can. J. For. Res. 39(4): 849-861. doi:10.1139/X09-015.

Orwig, D. A., and Foster, D. R. 1998. Forest Response to the Introduced Hemlock Woolly Adelgid in Southern New England, USA. J. Torrey Bot. Soc. 125(1): 60-73.

Orwig, D. A., Thompson, J. R., Povak, N. A., Manner, M., Niebyl, D., and Foster, D. R. 2012. A foundation tree at the precipice: Tsuga canadensis health after the arrival of Adelges tsugae in central New England. Ecoshpere 3(1): 1-16. 
Oten, K. L. F., Cohen, A. C., and Hain, F. P. 2014. Stylet Bundle Morphology and Trophically Related Enzymes of the Hemlock Woolly Adelgid (Hemiptera: Adelgidae). Ann. Entomol. Soc. Am. 107(3): 680-690.

Perboni, A. T., Cassol, D., da Silva, F. S. P., Silva, D. M., and Bacarin, M. A. 2012. Chlorophyll a fluorescence study revealing effects of flooding in canola hybrids. Biologia (Bratisl). 67(2): 338-346. doi:10.2478/s11756-012-0006-0.

Pezet, J., Elkinton, J., Gomez, S., McKenzie, E. A., Lavine, M., and Preisser, E. 2013. Hemlock Woolly Adelgid and Elongate Hemlock Scale Induce Changes in Foliar and Twig Volatiles of Eastern Hemlock. J. Chem. Ecol. doi:10.1007/s10886-013-0300-5.

Pontius, J. A., Hallett, R. A., and Jenkins, J. C. 2006. Foliar Chemistry Linked to Infestation and Susceptibility to Hemlock Woolly Adelgid (Homoptera: Adelgidae). Environ. Entomol. 35(1): 112-120. doi:10.1603/0046-225X-35.1.112.

Pontius, J., Hallett, R., and Martin, M. 2005a. Assessing hemlock decline using visible and nearinfrared spectroscopy: indices comparison and algorithm development. Appl. Spectrosc. 59(6): 836-43. doi:10.1366/0003702054280595.

Pontius, J., Hallett, R., and Martin, M. 2005b. Using AVIRIS to assess hemlock abundance and early decline in the Catskills, New York. Remote Sens. Environ. 97(2): 163-173. doi:10.1016/j.rse.2005.04.011.

Radville, L., Chaves, A., and Preisser, E. L. 2011. Variation in plant defense against invasive herbivores: evidence for a hypersensitive response in eastern hemlocks (Tsuga canadensis). J. Chem. Ecol. 37(6): 592-7. doi:10.1007/s10886-011-9962-z.

Rock, B. N., Hoshizaki, T., and Miller, J. R. 1988. Comparison of in situ and airborne spectral measurements of the blue shift associated with forest decline. Remote Sens. Environ. 24(1): 109-127. doi:10.1016/0034-4257(88)90008-9.

Rock, B. N., Vogelmann, J. E., Williams, D. L., Vogelmann, A. F., and Hoshizaki, T. 1986. Remote detection of forest damage. Bioscience 36(7): 439-445.

Rock, B. N., Williams, D. L., Moss, D. M., Lauten, G. N., and Kim, M. 1994. High-Spectral Resolution Field and Laboratory Optical Reflectance Measurements of Red Spruce and Eastern Hemlock Needles and Branches. Remote Sens. Environ. 47: 176-189.

Rouse, J. W., Haas, R. H., Schell, J. A., and Deering, D. W. 1974. Monitoring Vegetation Systems in the Great Plains with ERTS. pp. 48-62 Proceedings of the 3rd Earth Resouce Technology Satellite Symposium.

Royle, D. D., and Lathrop, R. G. 2002. Discriminating Tsuga canadensis Hemlock Forest Defoliation using Remotely Sensed Change Detection. J. Nematol. 34(3): 213-221. 
Rubino, L., Charles, S., Sirulnik, A. G., Tuininga, A. R., and Lewis, J. D. 2015. Invasive insect effects on nitrogen cycling and host physiology are not tightly linked. Tree Physiol. 35(2): 124-133. doi:10.1093/treephys/tpv004.

Strasser, R. J., Michael, M. T.-, and Srivastava, A. 2004. Analysis of the Fluorescence Transient. pp. 321-362 Chlorophyll a Fluorescence. Springer.

Strasser, R. J., Srivastava, A., and Tsimilli-Michael, M. 2000. The fluorescence transient as a tool to characterize and screen photosynthetic samples. pp. 443-480 Probing Photosynthesis: Mechanism, Regulation and Adaptation. Taylor and Francis, London.

Trotter, R. T., and Shields, K. S. 2009. Variation in winter survival of the invasive hemlock woolly adelgid (Hemiptera: Adelgidae) across the eastern United States. Environ. Entomol. 38(3): $577-87$.

Young, R. F., Shields, K. S., and Berlyn, G. P. 1995. Hemlock Woolly Adelgid (Homoptera: Adelgidae): Stylet Bundle Insertion and Feeding Sites. Ann. Entomol. Soc. Am. 


\section{Tables:}

Table 1. Forest structure and percent basal area occupied by hemlock for each of the four study properties.

\begin{tabular}{cccc}
\hline Site & Total Basal Area $\left(\mathbf{m}^{\mathbf{2}} / \mathbf{h a}\right)$ & Hemlock Basal Area (\%) & Plot Density $\left(\mathbf{s t e m s} / \mathbf{m}^{\mathbf{2}}\right)$ \\
\hline Massabesic Exp. Forest & 10897.0 & 23.2 & 0.015 \\
Northwood Meadows S.P. & 16297.0 & 46.2 & 0.033 \\
Rachael Carson N.W.R. & 5552.2 & 18.3 & 0.010 \\
Russell-Abbott State Forest & 7158.9 & 19.0 & 0.013 \\
\hline
\end{tabular}

Table 2. A summary table of the number of infested and non-infested samples by site.

\begin{tabular}{cccc}
\hline SITE & TREES SAMPLED & INFESTED & NON-INFESTED \\
\hline Massabesic Exp. Forest & 25 & 8 & 17 \\
Northwood Meadows S.P. & 23 & 23 & 0 \\
Rachael Carson N.W.R. & 24 & 3 & 21 \\
Russell-Abbott State Forest & 23 & 0 & 23 \\
\hline
\end{tabular}

Table 3. A summary table of the number of significantly different narrow bands, within each spectral region, by sample month and growth year from the 2012 sampling period.

\begin{tabular}{|c|c|c|c|c|c|c|}
\hline MONTH & $\begin{array}{l}\text { GROWTH } \\
\text { YEAR }\end{array}$ & $\begin{array}{c}\text { VISIBLE } \\
400-680 \mathrm{~nm}\end{array}$ & $\begin{array}{l}\text { RED EDGE } \\
680-750 \mathrm{~nm}\end{array}$ & $\begin{array}{c}\text { NIR } \\
750-1400 \mathrm{~nm}\end{array}$ & $\begin{array}{c}\text { MidIR } \\
1400-2500 \mathrm{~nm}\end{array}$ & TOTAL \\
\hline \multirow[t]{2}{*}{ JUNE } & 1 & 81 & 37 & 0 & 0 & 118 \\
\hline & 2 & 0 & 0 & 0 & 0 & 0 \\
\hline \multirow[t]{2}{*}{ JULY } & 1 & 57 & 1 & 0 & 4 & 62 \\
\hline & 2 & 18 & 0 & 0 & 0 & 18 \\
\hline \multirow[t]{2}{*}{ AUGUST } & 1 & 24 & 8 & 0 & 1 & 33 \\
\hline & 2 & 9 & 1 & 0 & 0 & 10 \\
\hline \multirow[t]{2}{*}{ SEPTEMBER } & 1 & 0 & 0 & 0 & 0 & 0 \\
\hline & 2 & 1 & 0 & 0 & 1 & 2 \\
\hline \multirow[t]{2}{*}{ OCTOBER } & 1 & 4 & 0 & 0 & 1 & 5 \\
\hline & 2 & 1 & 0 & 0 & 0 & 1 \\
\hline \multirow[t]{2}{*}{ NOVEMBER } & 1 & 27 & 0 & 0 & 1 & 28 \\
\hline & 2 & 0 & 0 & 3 & 26 & 29 \\
\hline \multirow{2}{*}{ DECEMBER } & 1 & 0 & 0 & 0 & 2 & 2 \\
\hline & 2 & 3 & 0 & 2 & 37 & 42 \\
\hline
\end{tabular}


Table 4. Z-scores and corresponding $P$-values of Wilcoxon's Tests.

\begin{tabular}{cccccccccc}
\hline & & \multicolumn{2}{c}{ REIP } & \multicolumn{2}{c}{ NDVI } & \multicolumn{2}{c}{ MSI } & \multicolumn{2}{c}{ NIR 3/1 } \\
MONTH & GROWTH YEAR & $\mathbf{Z}$ & Prob $>|\mathbf{Z}|$ & $\mathbf{Z}$ & $\mathbf{P r o b}>|\mathbf{Z}|$ & $\mathbf{Z}$ & $\mathbf{P r o b}>|\mathbf{Z}|$ & $\mathbf{Z}$ & $\mathbf{P r o b}>|\mathbf{Z}|$ \\
\hline June & 1 & 0.44771 & 0.6544 & 1.27775 & 0.2013 & 1.02220 & 0.3067 & 1.34312 & 0.1792 \\
& 2 & -0.69499 & 0.4871 & 0.86796 & 0.3854 & 0.75290 & 0.4515 & -0.28932 & 0.7723 \\
July & 1 & 0.19636 & 0.8443 & 0.84939 & 0.3957 & -0.45736 & 0.6474 & 0.45695 & 0.6477 \\
& 2 & -0.13067 & 0.8960 & 0.97919 & 0.3275 & -2.15614 & $\mathbf{0 . 0 3 1 1 *}$ & -0.84863 & 0.3961 \\
August & 1 & 1.62938 & 0.1032 & 1.52075 & 0.1283 & -1.03042 & 0.3028 & -1.46428 & 0.1431 \\
& 2 & -1.03270 & 0.3017 & -0.16270 & 0.8708 & -1.19400 & 0.2325 & -2.22354 & $\mathbf{0 . 0 2 6 2} *$ \\
September & 1 & 1.85073 & 0.0642 & 1.19488 & 0.2321 & -1.24735 & 0.2123 & -1.46428 & 0.1431 \\
& 2 & -0.16366 & 0.8700 & -1.57856 & 0.1144 & -0.86836 & 0.3852 & -0.65127 & 0.5149 \\
October & 1 & 1.03985 & 0.2984 & 0.93741 & 0.3485 & -2.46432 & $\mathbf{0 . 0 1 3 7 *}$ & -2.51620 & $\mathbf{0 . 0 1 1 9}$ \\
& 2 & 0.14871 & 0.8818 & -0.29587 & 0.7673 & -2.16860 & $\mathbf{0 . 0 3 0 1 *}$ & -2.56422 & $\mathbf{0 . 0 1 0 3 *}$ \\
November & 1 & 0.91472 & 0.3603 & 1.37578 & 0.1689 & -2.41749 & $\mathbf{0 . 0 1 5 6 *}$ & -2.41749 & $\mathbf{0 . 0 1 5 6 *}$ \\
& 2 & -0.91884 & 0.3582 & -1.24141 & 0.2145 & -2.15421 & $\mathbf{0 . 0 3 1 2} *$ & -2.41533 & $\mathbf{0 . 0 1 5 7 *}$ \\
December & 1 & 2.09080 & $\mathbf{0 . 0 3 6 5 *}$ & 0.00000 & 1.0000 & 0.00000 & 1.0000 & 0.12247 & 0.9025 \\
& 2 & 0.61237 & 0.5403 & 0.00000 & 1.0000 & 0.36742 & 0.7133 & 0.12247 & 0.9025 \\
\hline
\end{tabular}

* Denotes statistically significant at $\alpha=0.05$

Table 5. A summary table of the number of significantly different narrow bands, within each spectral region, by sample month and growth year from the 2013 sampling period.

\begin{tabular}{cccccc}
\hline WEEK & $\begin{array}{c}\text { VISIBLE } \\
\mathbf{4 0 0 - 6 8 0 ~} \mathbf{~ n m}\end{array}$ & $\begin{array}{c}\text { RED EDGE } \\
\mathbf{6 8 0 - 7 5 0} \mathbf{~ n m}\end{array}$ & $\begin{array}{c}\text { NIR } \\
\mathbf{7 5 0 - 1 4 0 0} \mathbf{~ n m}\end{array}$ & $\begin{array}{c}\text { MidIR } \\
\mathbf{1 4 0 0 - 2 5 0 0} \mathbf{~ n m}\end{array}$ & TOTAL \\
\hline 4 June & 0 & 0 & 3 & 3 & 6 \\
10 June & 3 & 0 & 0 & 2 & 5 \\
17 June & 1 & 0 & 28 & 1 & 30 \\
24 June & 0 & 0 & 0 & 0 & 0 \\
1 July & 44 & 12 & 0 & 4 & 60 \\
\hline
\end{tabular}

Table 6. Statistical test and associated $P$-values for the 2013 spectral health indices data.

\begin{tabular}{ccccccccc}
\hline & \multicolumn{2}{c}{ REIP } & \multicolumn{2}{c}{ NDVI } & \multicolumn{2}{c}{ MSI } & \multicolumn{2}{c}{ NIR 3/1 } \\
DATE & $\mathbf{Z}$ & Prob $>|\mathbf{Z}|$ & $\mathbf{Z}$ & Prob $>|\mathbf{Z}|$ & $\mathbf{Z}$ & Prob $>|\mathbf{Z}|$ & $\mathbf{Z}$ & Prob $>|\mathbf{Z}|$ \\
\hline $04 / 16 / 2013$ & 0.67316 & 0.5008 & 2.29783 & $\mathbf{0 . 0 2 1 6 *}$ & -0.83557 & 0.4034 & -0.00000 & 1.0000 \\
$10 / 06 / 2013$ & 1.18159 & 0.2374 & 0.62668 & 0.5309 & -1.04447 & 0.2963 & -0.21017 & 0.8335 \\
$17 / 06 / 2013$ & 1.58114 & 0.1138 & 1.47120 & 0.1412 & -0.83557 & 0.4034 & -0.52382 & 0.6004 \\
$24 / 06 / / 2013$ & 0.40988 & 0.6819 & 1.35554 & 0.1752 & -0.96825 & 0.3329 & -0.58621 & 0.5577 \\
$01 / 07 / 2013$ & 2.44718 & $\mathbf{0 . 0 1 4 4 *}$ & 2.30482 & $\mathbf{0 . 0 2 1 2 *}$ & -1.36194 & 0.1732 & -0.62668 & 0.5309 \\
\hline
\end{tabular}

* Denotes statistically significant at $\alpha=0.05$ 
Table 7. Results of Wilcoxon's Test on pigment concentration in infested vs. non-infested hemlock foliage.

\begin{tabular}{cccccccccc}
\hline & & \multicolumn{2}{c}{ CHL a } & \multicolumn{2}{c}{ CHL b } & \multicolumn{2}{c}{ CHLtot } & \multicolumn{2}{c}{ CAR } \\
MONTH GROWTH YEAR & $\mathbf{Z}$ & Prob $>|\mathbf{Z}|$ & $\mathbf{Z}$ & Prob $>|\mathbf{Z}|$ & $\mathbf{Z}$ & Prob $>|\mathbf{Z}|$ & $\mathbf{Z}$ & Prob $>|\mathbf{Z}|$ \\
\hline \multirow{2}{*}{ June } & 1 & 0.894427 & 0.3711 & 0.638877 & 0.5229 & 0.894427 & 0.3711 & -0.127775 & 0.8983 \\
& 2 & -0.520774 & 0.6025 & -0.636501 & 0.5244 & -0.520774 & 0.6025 & -0.636501 & 0.5244 \\
\multirow{3}{*}{ July } & 1 & 0.979187 & 0.3275 & 0.326396 & 0.7441 & 0.979187 & 0.3275 & 0.718070 & 0.4727 \\
& 2 & -0.326396 & 0.7441 & -0.065279 & 0.9480 & -0.065279 & 0.9480 & -0.326396 & 0.7441 \\
\multirow{2}{*}{ August } & 1 & -1.620185 & 0.1052 & -1.620185 & 0.1052 & -1.620185 & 0.1052 & -1.620185 & 0.1052 \\
& 2 & -0.694365 & 0.4875 & 0.000000 & 1.0000 & -0.694365 & 0.4875 & 0.694365 & 0.4875 \\
\hline
\end{tabular}

* Denotes statistically significant at $\alpha=0.05$

Table 8. Results of Wilcoxon's Test on the 2013 extraction data.

\begin{tabular}{cccccccccc}
\hline & \multicolumn{2}{c}{ CHLa } & \multicolumn{2}{c}{ CHL b } & \multicolumn{2}{c}{ CHLtot } & \multicolumn{2}{c}{ CARtot } \\
DATE & $\mathbf{Z}$ & Prob $>|\mathbf{Z}|$ & $\mathbf{Z}$ & Prob $>|\mathbf{Z}|$ & $\mathbf{Z}$ & Prob $>|\mathbf{Z}|$ & $\mathbf{Z}$ & Prob $>|\mathbf{Z}|$ \\
\hline $04 / 06 / 2013$ & 2.078805 & $\mathbf{0 . 0 3 7 6 *}$ & 1.322876 & 0.1859 & 1.927619 & 0.0539 & 2.759141 & $\mathbf{0 . 0 0 5 8 *}$ \\
$10 / 06 / 2013$ & -0.037796 & 0.9698 & 0.264575 & 0.7913 & 0.037796 & 0.9698 & 0.264575 & 0.7913 \\
$17 / 06 / 2013$ & 1.700840 & 0.0890 & 2.003212 & $\mathbf{0 . 0 4 5 2 *}$ & 1.776433 & 0.0757 & -0.113389 & 0.9097 \\
$24 / 06 / 2013$ & 1.626346 & 0.1039 & 0.000000 & 1.0000 & 1.060660 & 0.2888 & 2.050610 & $\mathbf{0 . 0 4 0 3 *}$ \\
$01 / 07 / 2013$ & 2.305583 & $\mathbf{0 . 0 2 1 1 *}$ & 0.000000 & 1.0000 & 1.776433 & 0.0757 & -0.642540 & 0.5205 \\
\hline
\end{tabular}

* Denotes statistically significant at $\alpha=0.05$

Table 9. Results of Wilcoxon's Test on fluorescence parameters.

\begin{tabular}{ccccccc}
\hline & \multicolumn{2}{c}{ Fv/Fm } & \multicolumn{2}{c}{ PIabs } & \multicolumn{2}{c}{ PItot } \\
DATE & $\mathbf{Z}$ & Prob $>|Z| Z \mid$ & $\mathbf{Z}$ & Prob $>|\mathbf{Z}|$ & $\mathbf{Z}$ & Prob $>|\mathbf{Z}|$ \\
\hline $04 / 06 / 2013$ & 0.908251 & 0.3637 & 1.960676 & $\mathbf{0 . 0 4 9 9 *}$ & 2.373321 & $\mathbf{0 . 0 1 7 6 *}$ \\
$10 / 06 / 2013$ & 0.430132 & 0.6671 & -1.220062 & 0.2224 & -2.750000 & $\mathbf{0 . 0 0 6 0 *}$ \\
$17 / 06 / 2013$ & -0.407646 & 0.6835 & 0.523877 & 0.6004 & 1.338797 & 0.1806 \\
$24 / 06 / 2013$ & 0.635869 & 0.5249 & 2.569209 & $\mathbf{0 . 0 1 0 2 *}$ & 2.915619 & $\mathbf{0 . 0 0 3 5 *}$ \\
$01 / 07 / 2013$ & -0.400880 & 0.6885 & -3.790000 & $\mathbf{0 . 0 0 0 2 *}$ & -4.990000 & $<.0001 *$ \\
\hline
\end{tabular}

* Denotes statistically significant at $\alpha=0.05$ 


\section{Figure Captions:}

Fig. 1. A map of the region of indicating the locations of the study plots.

Fig. 2. Reflectance difference as measured in percent (left column), and sensitivity curves (right column), of first year foliage from June through December of 2012. Negative difference (\%) values indicated wavelengths at which infested foliage exhibited lesser reflectance than noninfested foliage. Sensitivity curves highlight the reflectance wavelengths at which a response to HWA infestation may be detected. Vertical lines at $680 \mathrm{~nm}, 750 \mathrm{~nm}$, and $1400 \mathrm{~nm}$ denote the visible, red edge, NIR and MidIR spectral regions.

Fig. 3. Graphs indicating the spectral bands that were statistically significant when comparing infested and non-infested foliage from the 2012 sampling period. The graphs are arranged by month in rows, and by growth year in columns. Statistical significance is denoted by black markers below the 0.05 significance level line. Only p-values below 0.20 are shown. Vertical lines at $680 \mathrm{~nm}, 750 \mathrm{~nm}$, and $1400 \mathrm{~nm}$ denote the visible, red edge, NIR and MidIR spectral regions.

Fig. 4. Reflectance difference as measured in percent (left column), and sensitivity curves (right column), of second year foliage from June through December of 2012 . Vertical lines at $680 \mathrm{~nm}$, $750 \mathrm{~nm}$, and $1400 \mathrm{~nm}$ denote the visible, red edge, NIR and MidIR spectral regions.

Fig. 5. Outlier box plots of spectral health indices data for first year (left column) and second year (right column) growth by month in 2012 for infested and non-infested foliage. Asterisks indicate statistically significant differences $(\alpha=0.05)$ between infested and non-infested foliage. Sample size values for each month are noted in Figures 2 and 4.

Fig. 6. First year foliage reflectance difference as measured in percent (left column), and sensitivity curves (right column), from the 2013 Massabesic Experimental Forest data collection. 
Vertical lines at $680 \mathrm{~nm}, 750 \mathrm{~nm}$, and $1400 \mathrm{~nm}$ denote the visible, red edge, NIR and MidIR spectral regions.

Fig. 7. Graphs indicating the spectral bands that were statistically significant when comparing infested and non-infested foliage from the 2013 sampling period. Statistical significance is denoted by black markers below the 0.05 significance level line. Only p-values below 0.20 are shown. Vertical lines at $680 \mathrm{~nm}, 750 \mathrm{~nm}$, and $1400 \mathrm{~nm}$ denote the visible, red edge, NIR and MidIR spectral regions.

Fig. 8. Outlier box plots of spectral health indices data from the 2013 Massabesic Experimental Forest first year foliage. Asterisks indicate statistically significant $(\alpha=0.05)$ differences between infested and non-infested foliage. Sample size values for each week are noted in Figure 6.

Fig. 9. Chlorophyll data from the 2013 Massabesic Experimental Forest data collection comparing non-infested (dark grey) and HWA infested (light grey) hemlock foliage for first year growth. Asterisks indicate statistical differences $(\alpha=0.05)$ between infested and non-infested foliage for that week. For each week infested and non-infested groups $n=5$, except for 24 June infested foliage when $n=3$.

Fig. 10. Fluorescence parameter data indicating that infested foliage absorbed greater photon energy and had a greater photosynthetic performance index value. Asterisks indicate statistically significant $(\alpha=0.05)$ differences between infested and non-infested foliage.

Fig. 11A. Outlier box plots of weekly foliar moisture content values from the 2013 Massabesic Experimental Forest data collection. 11B. Correlation of the MSI to foliar moisture content values, indicating that as foliar moisture content decreased MSI values increased. 
Fig. 1

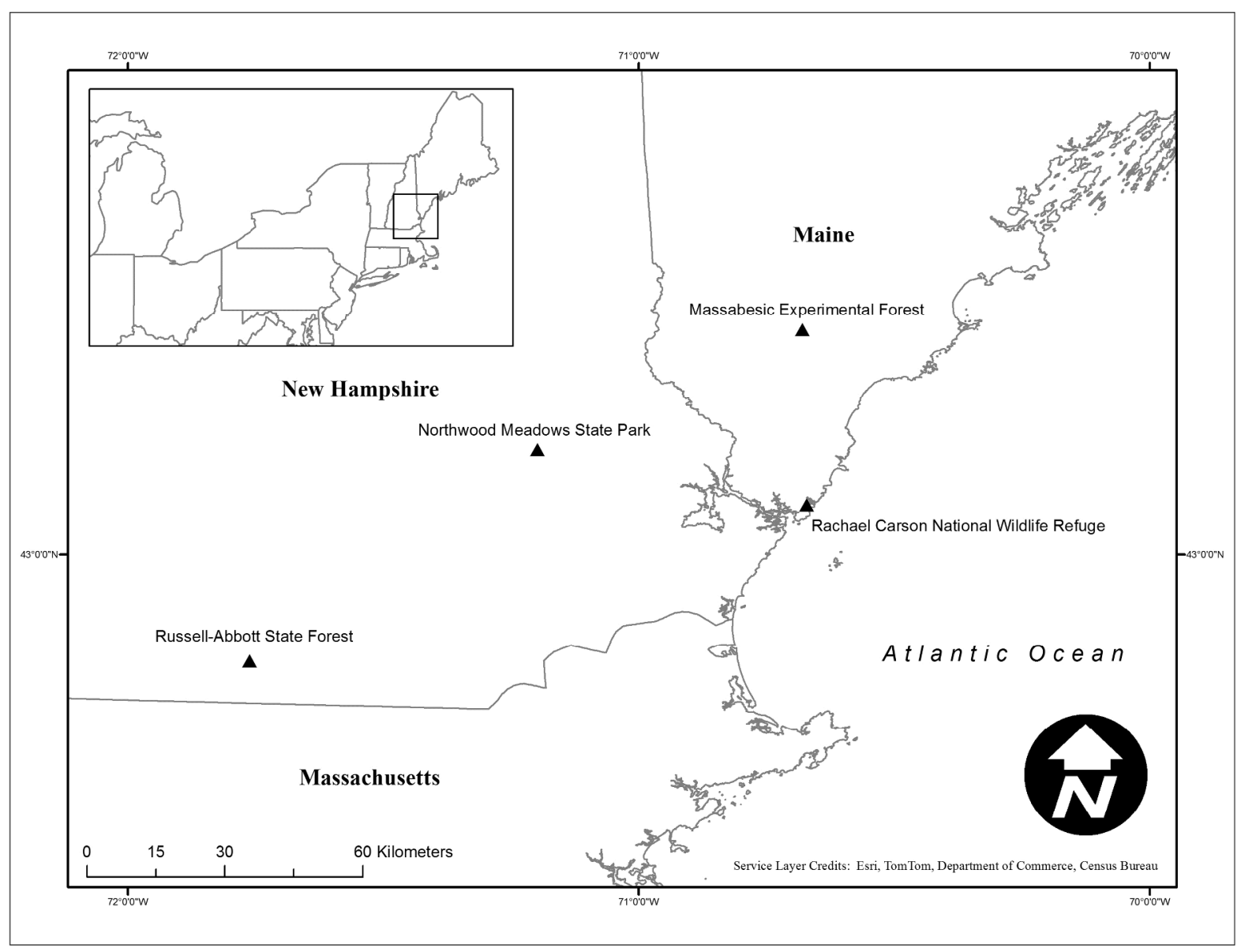


Fig. 2

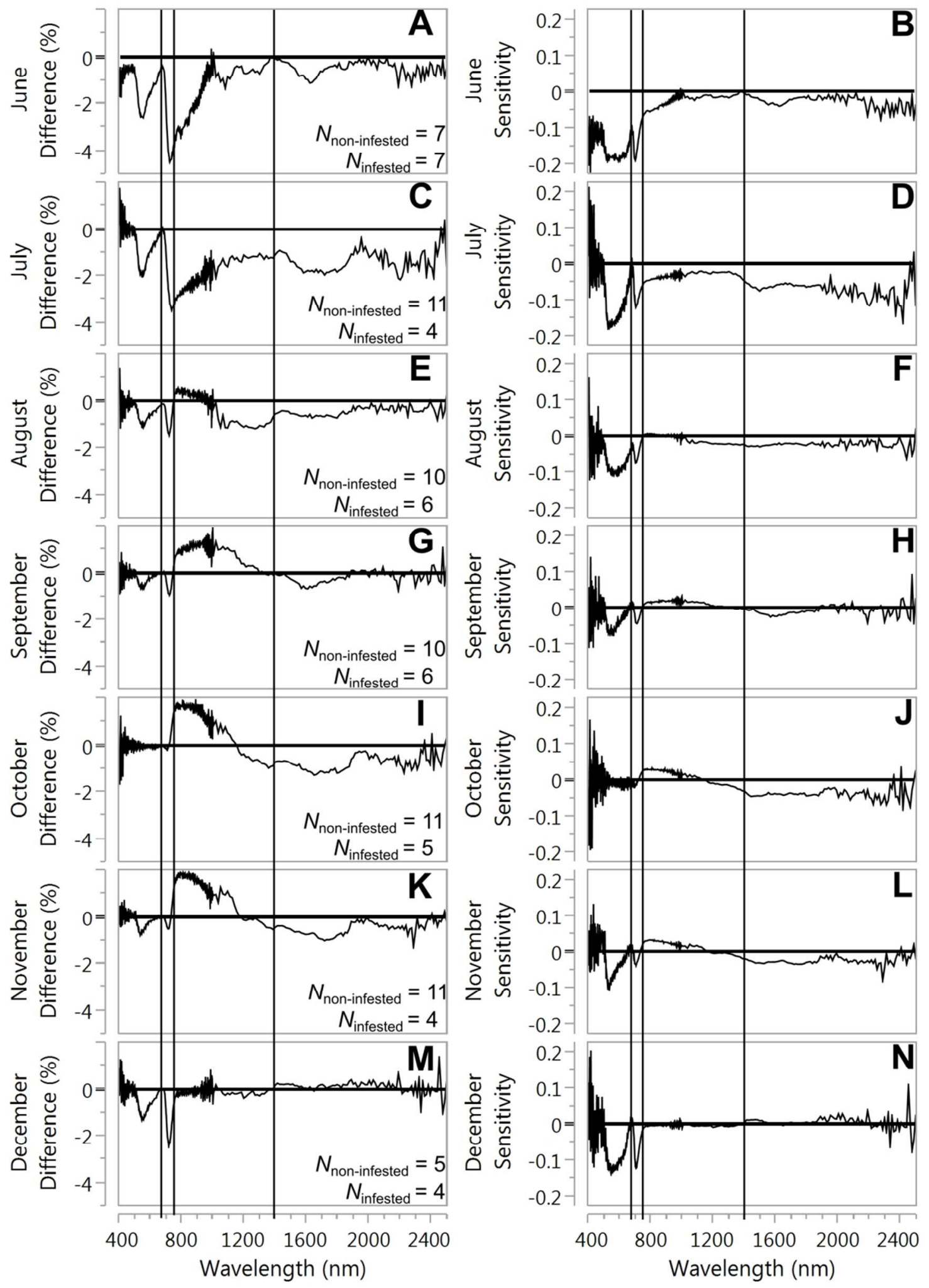


Fig. 3

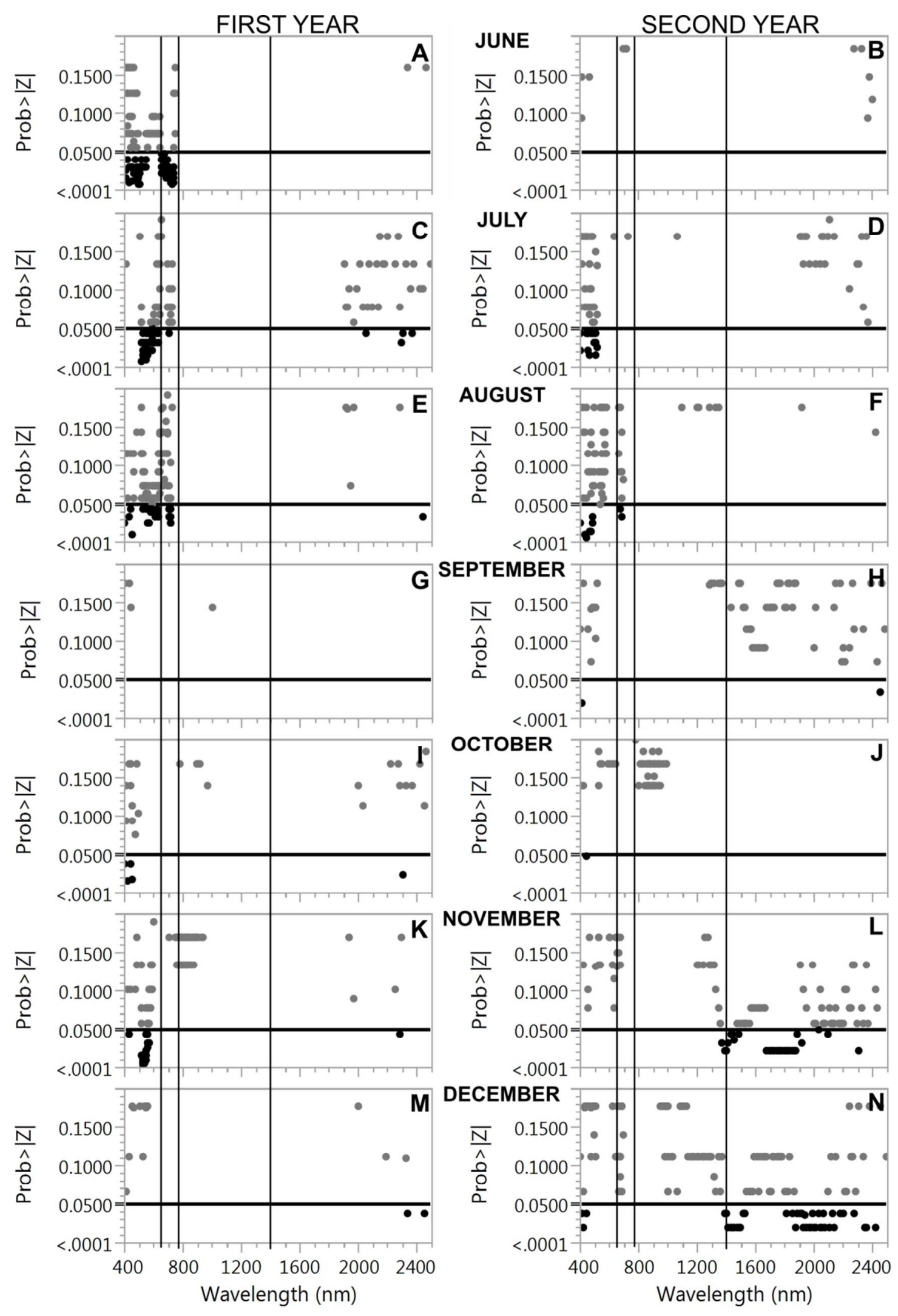


Fig. 4

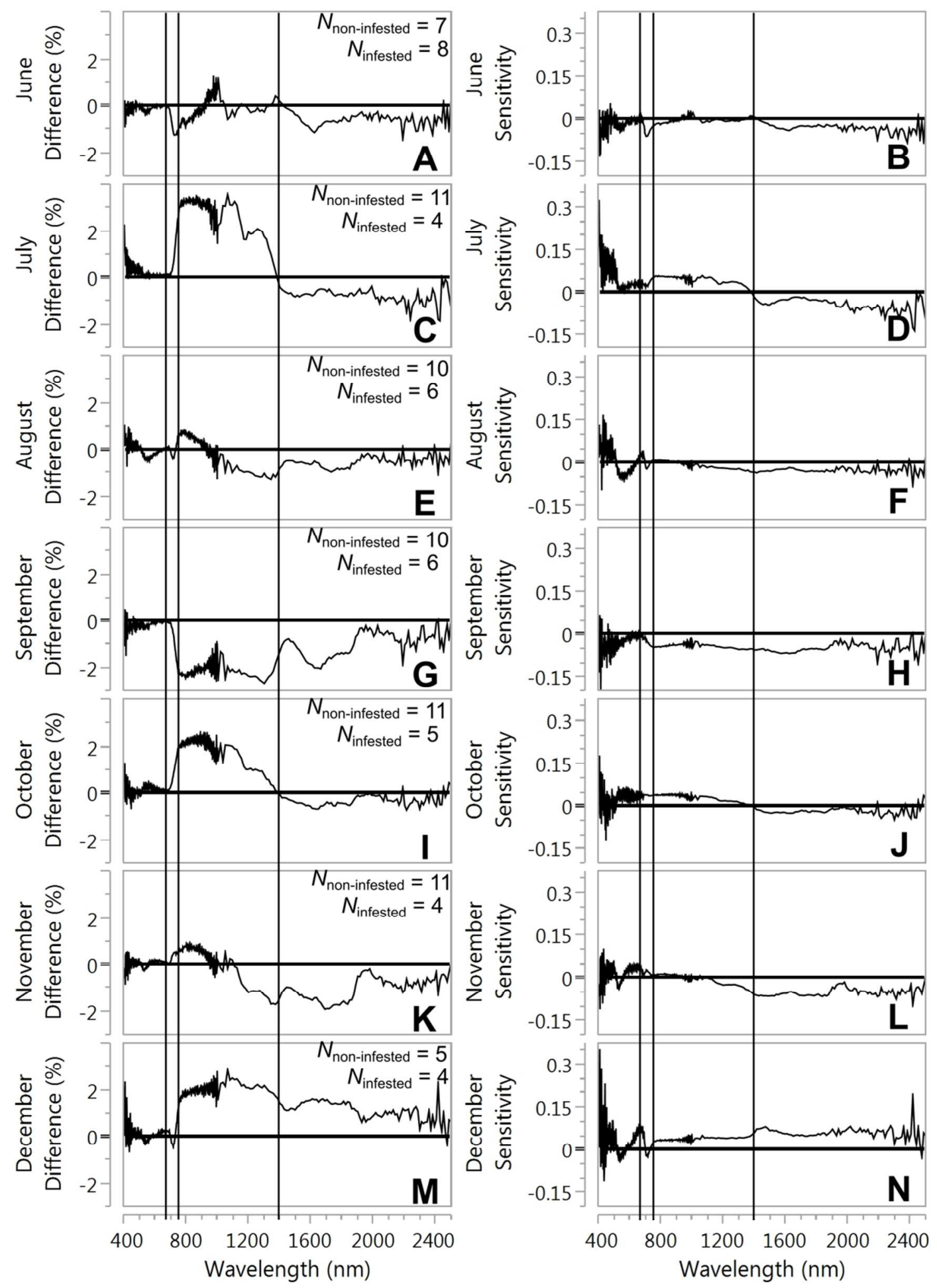


Fig. 5
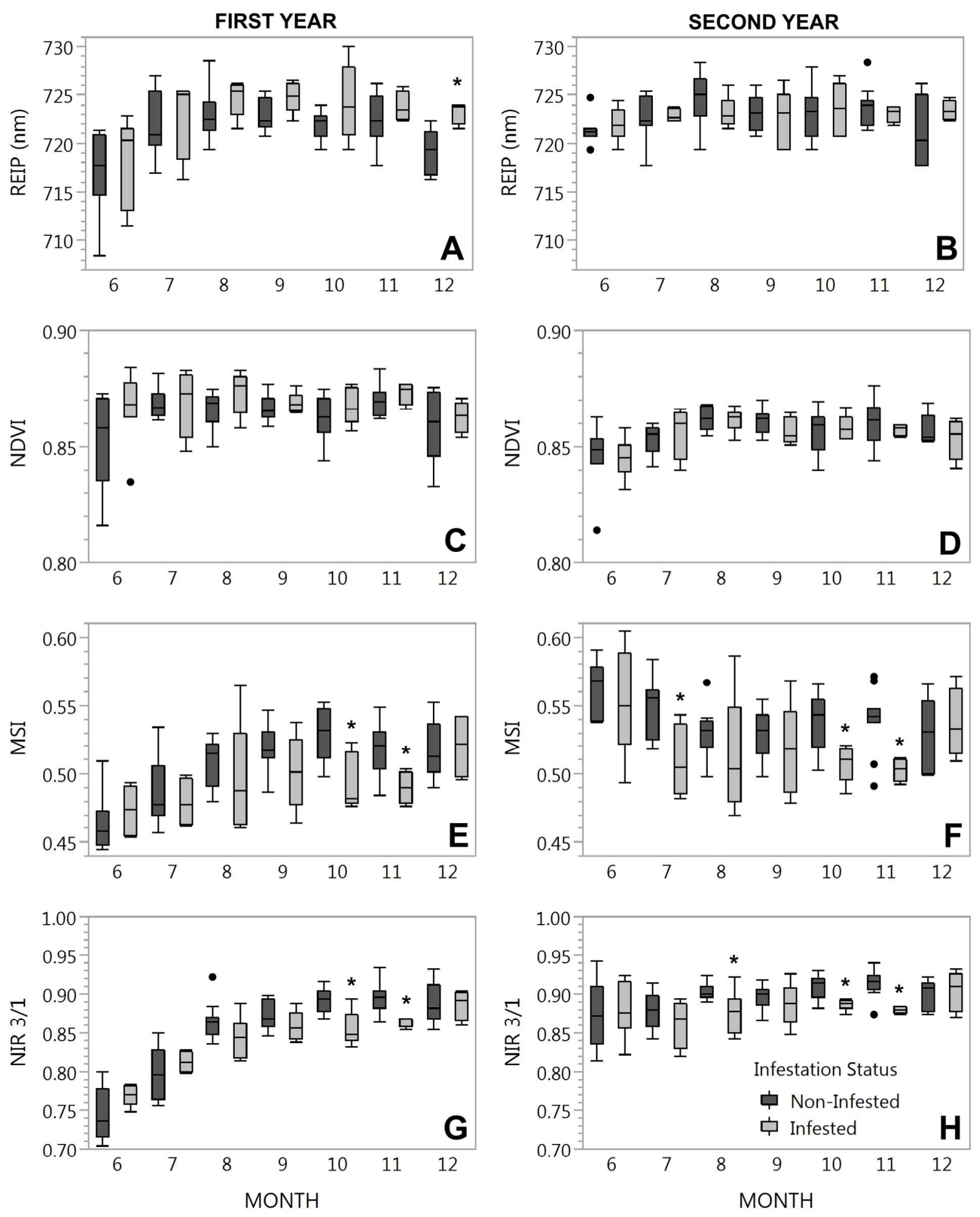
Fig. 6
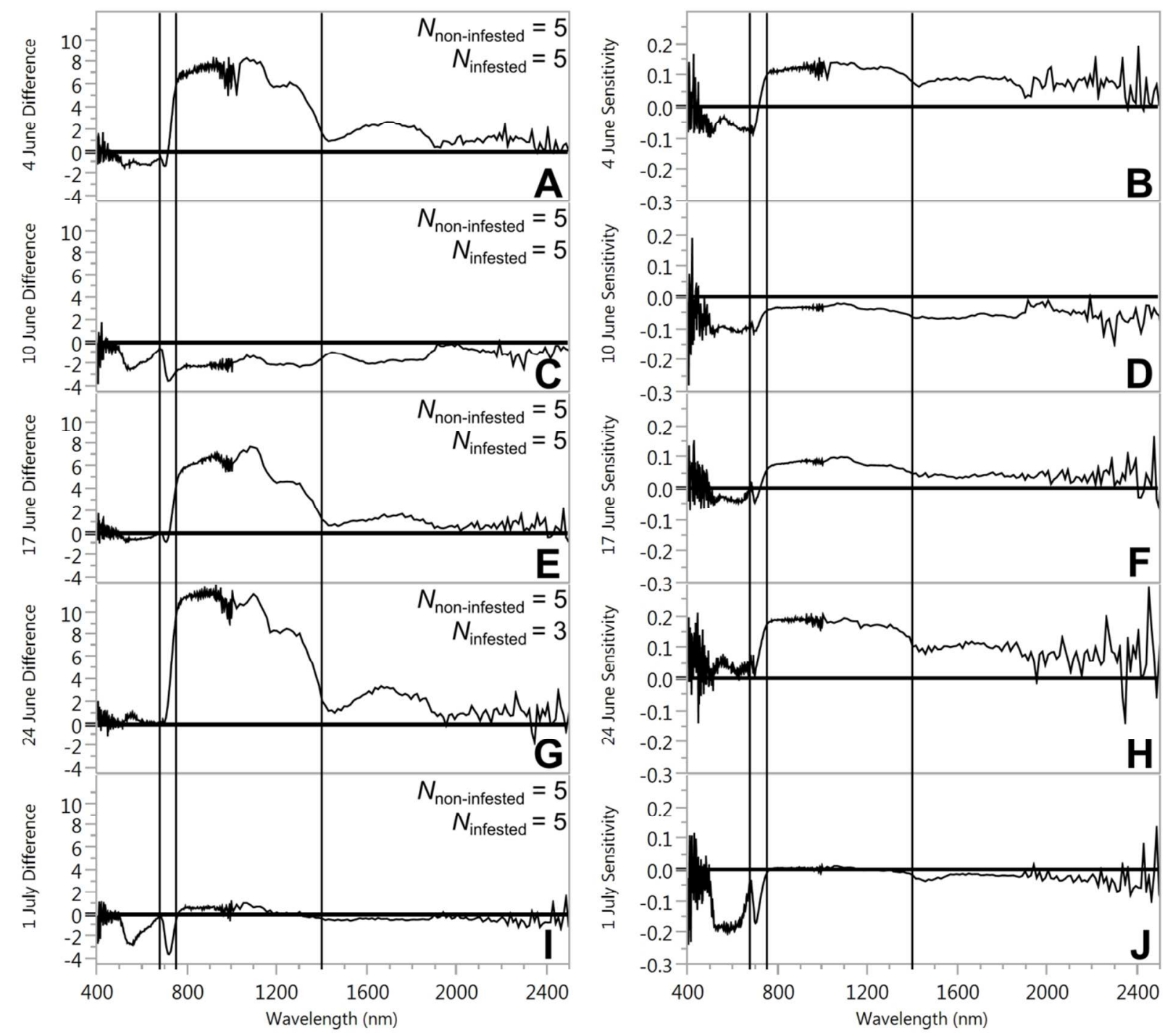
Fig. 7

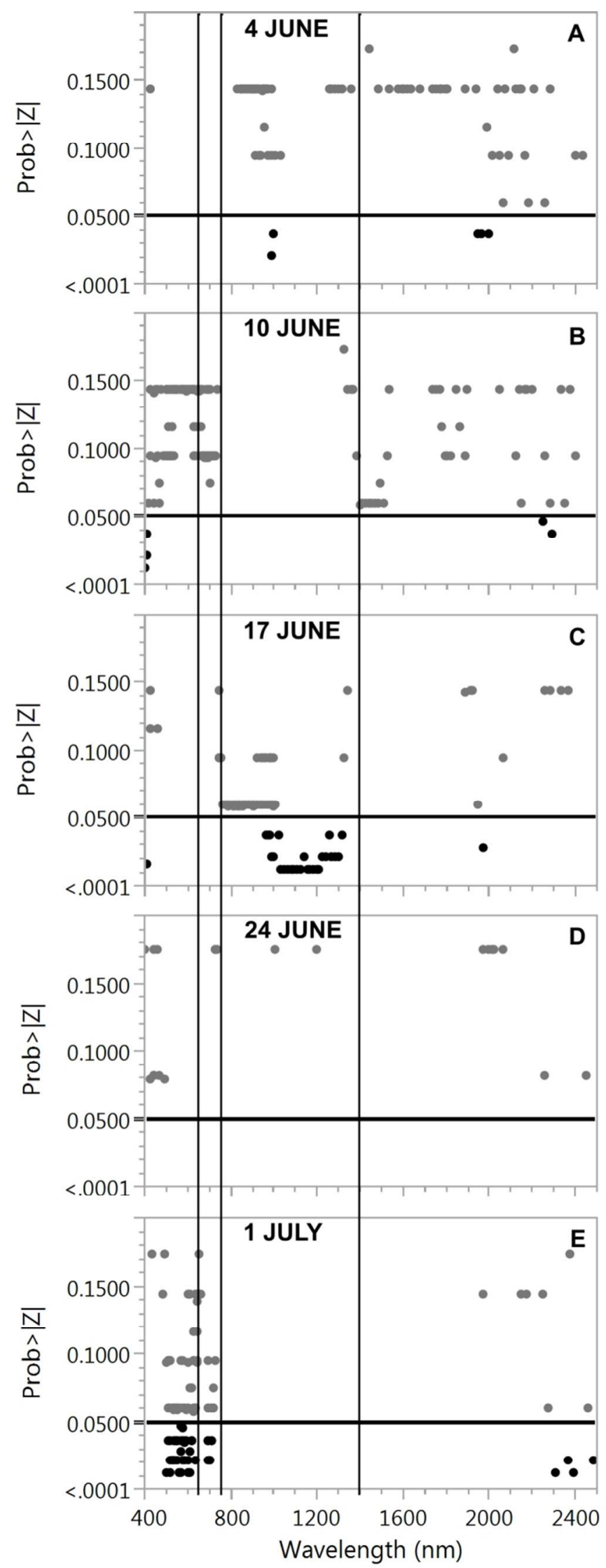

https://mc06.manuscriptcentral.com/cjfr-pubs 
Fig. 8
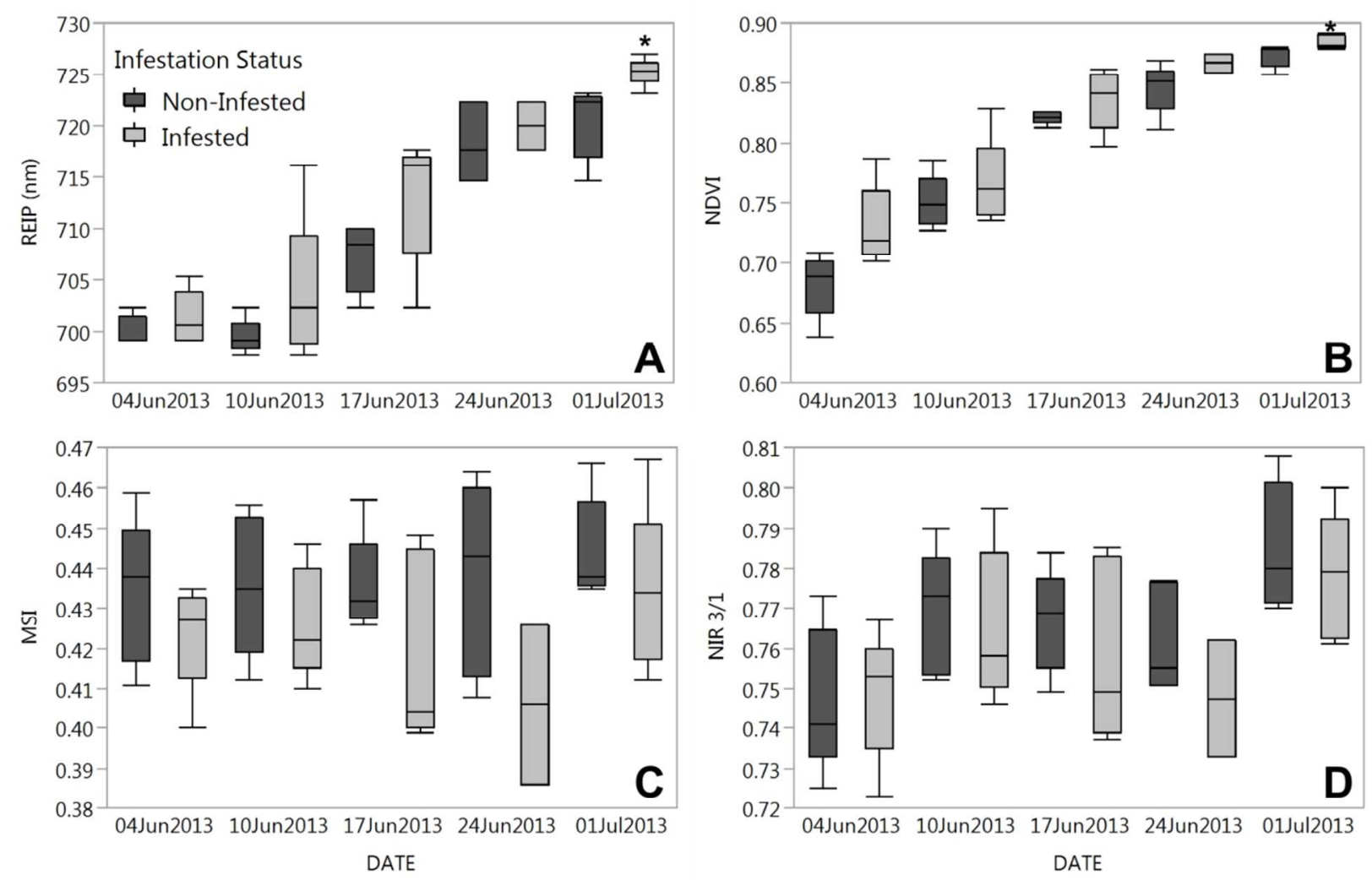
Fig. 9

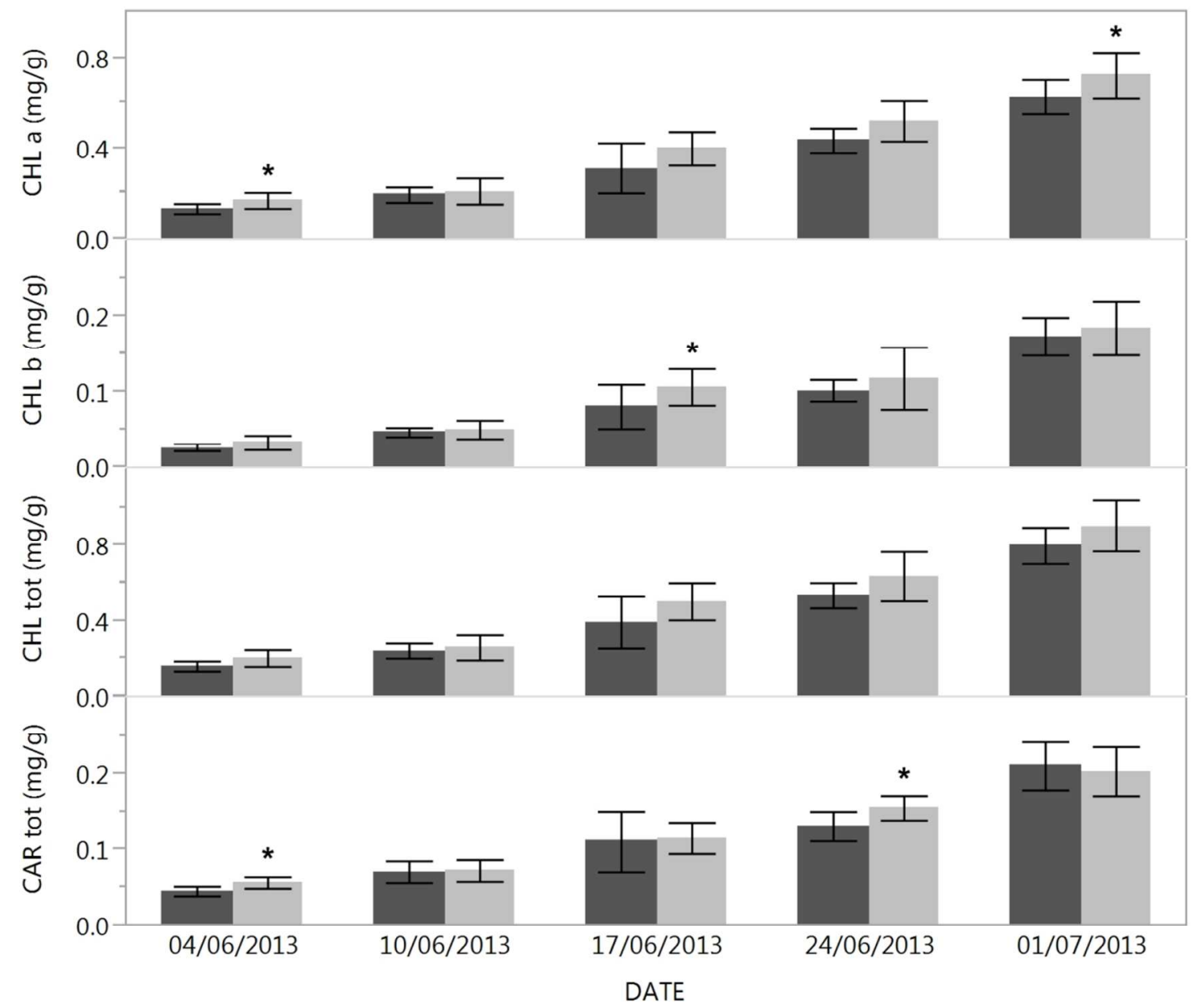


Fig. 10

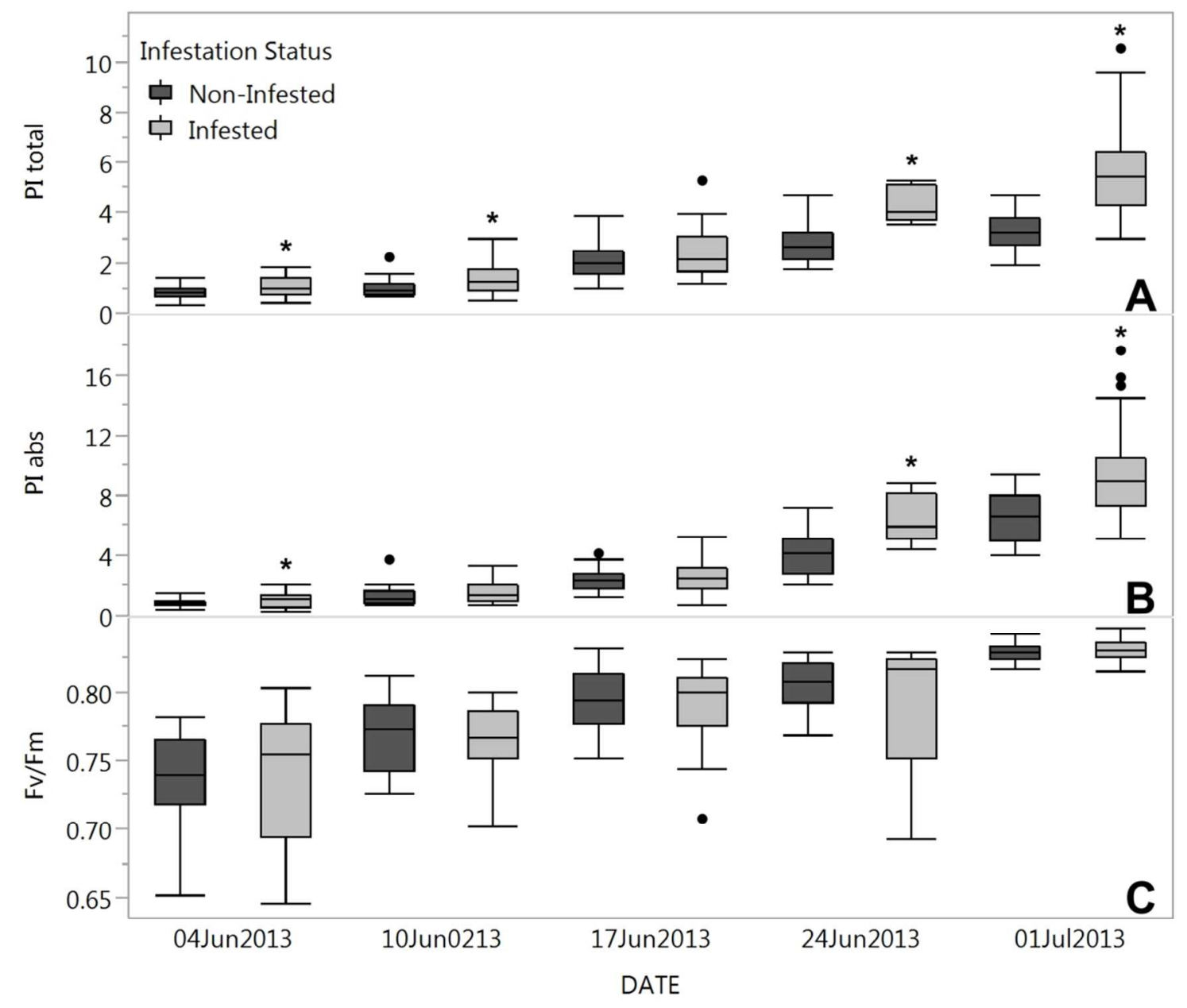


Fig. 11
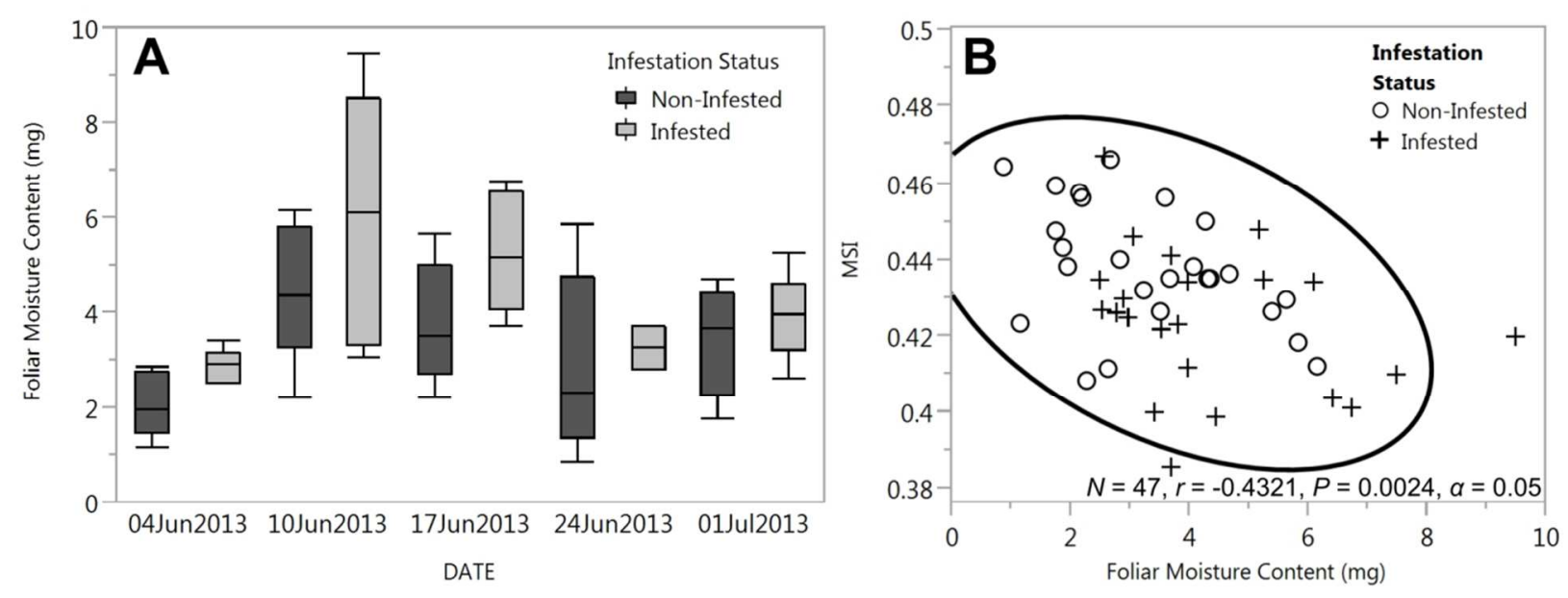